$\underset{{ }^{*} \text { Corresponding author }}{\text { Giuseppe Fallacara* }}$

Facoltà di Architettura

Politecnico di Bari via Orabona, 4

70125 Bari - Italia gfallacara@hotmail.com

\section{Fiore Resta}

Facoltà di Architettura

Politecnico di Bari via Orabona, 4

70125 Bari - Italia

fiore.resta@email.it

\section{Nicoletta Spallucci}

Facoltà di Architettura

Politecnico di Bari

via Orabona, 4

70125 Bari - Italia

nicla.spa@email.it

\section{Luc Tamboréro}

Ecole Nationale Supérieure d'Architecture Paris-Malaquais

14 , rue Bonaparte

75272 Paris - France mecastone@hotmail.fr

\section{Research}

\section{The Vault of the Hôtel de Ville in Arles}

Abstract. The vault of the Arles City Hall, or Hôtel de Ville, represents the architect's revenge on the corporations of masons. Completed in 1676, the relationship of span to rise of the vault make it the boldest work of masonry in Europe, and while this complex vault appears to be a unitary structure, two vaults actually share the work, leaning against each other on the big arch. Bibliographic and archival research showed that surveys of the vault were missing; the only ancient survey was lost in the 1970s. A recent survey campaign made an analysis possible, leading to a hypothesis about the architect Mansart's choices, based on hypothetical solutions to resolve the formal construction issues of the vault. A connoisseur of geometry and optics, Mansart knew that the human eye was unable to perceive the exact geometry of a surface. Knowing that he couldn't control the intersections of vault portions and then the joints of the rows in the space, he introduced a solution that involved drawing the intersections in plan and then projecting them on the vault to obtain the spatial intersections. No further constructions of the bold type followed the vaulted space in the Hôtel de ville, because the spatial research that linked the new discipline (stereotomy) to the quality of architectural space had by then come to an end.

Keywords: masonry construction, vaults, stereotomy,

La voûte de l'Hôtel de ville d'Arles est le chef d'oeuvre de la stéréotomie française [Perouse de Montclos 1983: 123-126]

\title{
Introduction
}

The vault of the Hôtel de ville, or city hall, in Arles symbolises the revenge of the figure of the architect on the guilds of masons. Completed in 1676, the relationship between the span and the height of the vault of the vestibule make it still today the most daring creation in dressed stone in all Europe. It is ingeniously conceived to give the illusion of being a single structure, while in reality it is composed of two vaults that share the work, leaning against each other on the large arch. The special feature of the stereotomy consists in the fact that the surface was not conceived as an assembly of portions of canonic geometric volumes, but is an expression of a process of laying out lines in plan (a wire frame) and projecting this onto the vault.

It was just in this period, in December 1671, that the Académie Royale d'Architecture was founded, and thus the vault was built at a moment in history when the figure of the architect clashed with that of the tailleur de pierre, or stonecutter. This conflict can be dated back to 1644, to the debate between Curabelle, who represented the guild of masons, and the geometer Girard Desargues. The vault represents the last work of stereotomy of this level of complexity ever constructed. The separation of roles 
introduced by the Académie led architects and engineers to prefer forms that were sobre and regular, for aesthetic reasons and above all, for structural reasons.

\section{The history of the Arles Hôtel de ville}

The Hotel de ville was built to satisfy the need for a space of sufficient size to house the Arles city council meetings. Since the Middle Ages, the city administration in Arles had been under the control of four consuls - two noble and two bourgeois chosen from among the members of the city council - who met annually. The life of the city was regulated by the resolutions of this council. With the organisation of the city administration at the end of the fourteenth century, the city council realised that they needed a place of their own in which to meet.

Construction on the new city hall (fig. 1) lasted almost twenty years, with the building entrusted to the greatest architects of the day, including La Valfenière, Puget, Jacques Peytret and Jules Hardouin-Mansart. Following demolition of the old city hall, some weeks after construction had begun work was stopped for a change in the design brought about by the decision to purchase the house belonging to Alphante di Bibion, located to the east of the site of the city hall, where the clock tower was. This modification led to an increase in both width and height of planned building.

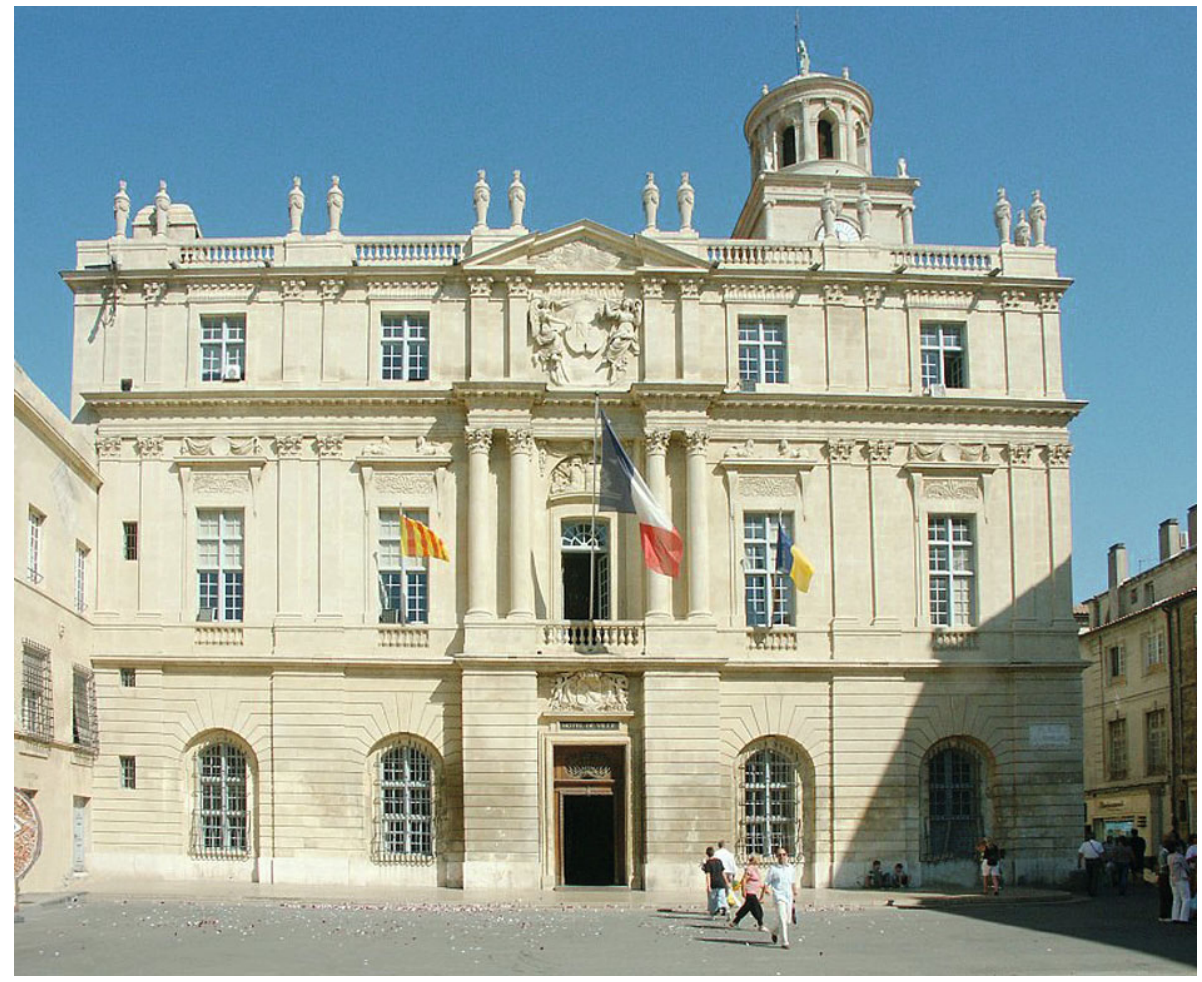

Fig. 1. The present day façade of the Arles Hôtel de ville on the Place de la République

The design presented by La Valfenière was fairly different from that later adopted. The poor quality of the work made it necessary to demolish what had previously been constructed all the way down to the foundations. 
Only Mansart dared to incorporate the old clock tower in its entirety within the perimeter of the new building. The tower was built in the form of an irregular trapezoid placed slightly obliquely with respect to the alignment of the two spaces. Mansart's design called for a large central space conceived without intermediate supporting piers, with a vault that covered it entirely with a height of only 1 canne, a local unit of length equal to just over $2 \mathrm{~m}$. At that time, architects and stonecutters had very different views about and training in geometry. Mansart chose Jacques Peytret, a painter, engraver and architect, to accompany him to Bèziers, explaining to him along the way the design and the techniques to be used in its execution.

When he returned to Arles, Peytret was already carrying the drawings of the panneaux for the construction of the vault. Unfortunately, he did not entirely follow the architect's design, believing it to be too daring: he decided to raise the vault by one and a half pan (about $30 \mathrm{~cm}$ ).

On 29 August 1675 the last stone was placed in the vault, and the centering removed.

\section{The debates at the Académie Royale d'Architecture}

The Académie Royale d'Architecture was created in Paris in 1671, thanks to the efforts of Jean-Baptiste Colbert and the architect François Blondel. The Académie debates concerned the issues of the day: the current status of the architectural profession, and the problem of structural stability of vaults. The vault in Arles was the focus of debates regarding the relationships between mechanics, geometry, and architecture. Its irregularity made it impossible to compare to other works of stereotomy.

One key figure in the history of stereotomy and mechanics applied to construction is Philippe de La Hire, professor at both the Académie Royale d'Architecture and the Collége Royale, a member of the Paris Académie Royale des Sciences, and authoritative advisor to Louis XIV. De La Hire addressed the problem of vaults both by examining the aspects relative to geometry and stonecutting, and by studying the problem of determining the thrust.

Consider that the breaking point of the arch is located close to that angle beyond which friction is no longer able to guarantee equilibrium; this is found at approximately $45^{\circ}$. The stones of the upper part, comprised between the two joints of rupture behave as a single block, and the kinematics is like that of a large keystone that pushes against the sides of the vault.

The problem that provoked the discussions could have been one of those given to the students of the Académie Royale d'Architecture: design a large vaulted vestibule, comprising two adjacent bays that together form a space some $16 \mathrm{~m}$ square, without intermediate supports, with a rise equal to a ninth of the span.

\section{Analysis of the vault of the Hôtel de ville}

The vaulted space of the Arles city hall aroused quite a bit of interest on the part of the professors in the Faculty of Architecture at the Politecnico di Bari, who decided to use it as a case study in a degree program. Following a survey campaign, it was possible to formulate several hypotheses for an analysis that might make it possible to retrace and understand Mansart's design principles. The hypotheses are obviously subjective, and are dictated by the deductions and interpretations deriving from the survey. 
The interpretation of these kinds of proportional systems, which are as legible in plan as they are in elevation, go from the decomposition of the work in cannes and pans to the recomposition of the parts according to the rules of the golden rectangle, finally arriving at the intuition of the purely sensory equilibrium by means of perspective corrections.

The unit of measurement used by classical architects to proportion the whole is the module, which is determined by the diameter of the column shaft measured at its base: this is the fundamental building block of the entire system. Once that unit of measure (the module) has been established, all architectural elements, frames, mouldings, and so forth are determined as whole multiples or simple fractions of the module. The dimension established is used as a reference for all others obtained according to predetermined ratios.

On 14 November 1583, by order of Henri III, it was decreed that all the various weights and measures of Provence were to be unified in conformance with the other units of measure of southern France. The unit of measure became the canne, equal to $2.044 \mathrm{~m}$. Each canne was divided into 8 pans, each equal to approximately $0.25 \mathrm{~m}$.

\section{Analysis in modules}

It has emerged that in plan the proportioning module measures exactly equal to 8 cannes by 8 cannes.

Analysis of the proportions in the elevations has confirmed what was indicated in archival documents: the facade in Plan de la Cour is larger than that in Place de la République, measuring 15 cannes, 4 pans as opposed to the 14 cannes, 6 pans of the present-day main façade (fig. 2).
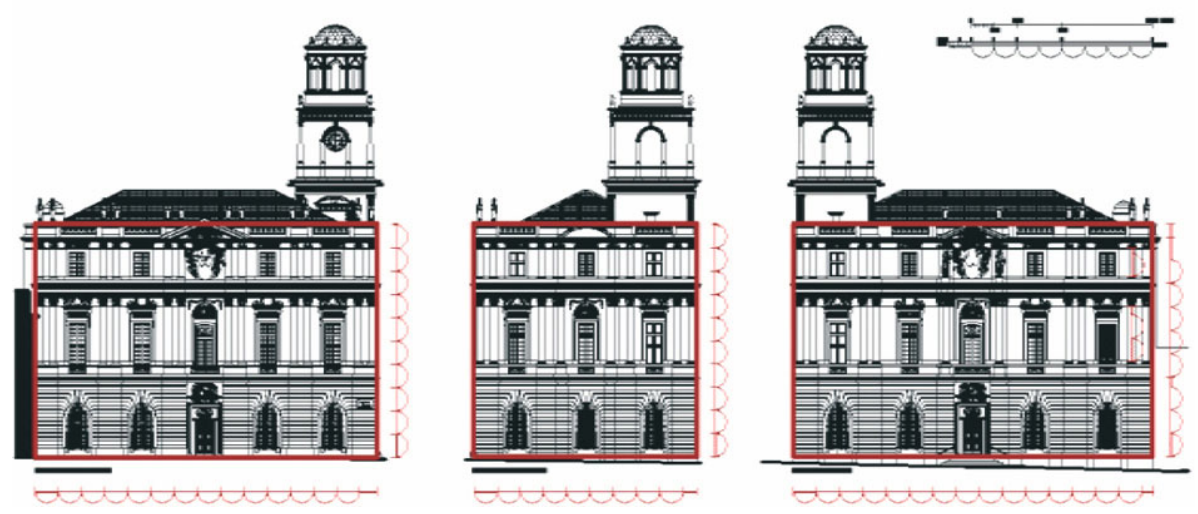

Fig. 2. Analysis of the facades in Place de la République, in rue de l'Hôtel de Ville and in Plan de la Cour, in canne and pan, the ancient French units of measurement

Two golden rectangles can be identified in the structure of the vault, one in which the large vault is inscribed, and the second for the small vault. The two rectangles follow two proportional systems: one based on sub-modules of the rectangle itself, the other on the system of the cannes (fig. 3). The two units of measure closely approximate each other, differing by only 2 menu $(0.032 \mathrm{~m})$. In particular, the rectangle of the large vault measures $8 \times 5$ modules, where each module is equal to the eighth part of the base of the rectangle. The sum of the heights of the largest rectangle and the rectangle that 
circumscribes the small vault is 8 modules. When read using the system of cannes, the largest rectangle measures 8 cannes, 2.5 pans by 5 cannes, 1 pan. The small rectangle measures 3 cannes, 1 pan (fig. 4).
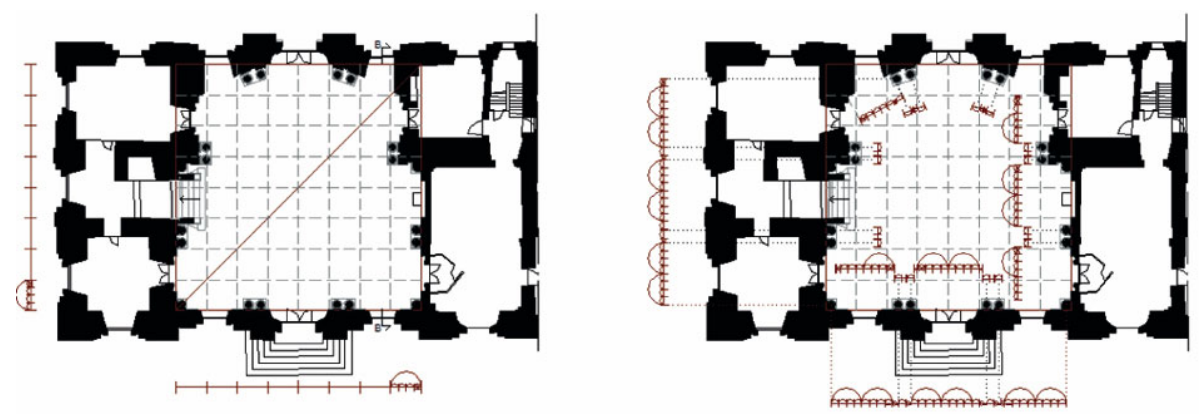

Fig. 3. Analysis of the plan in canne and pan
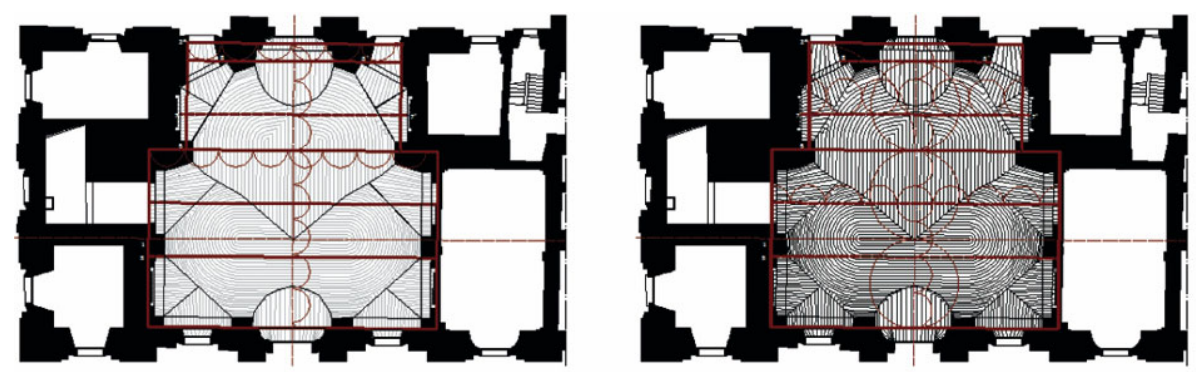

Fig. 4. Analysis of the vault with canne and pan

The system is in base 8: the interior columns are 2 cannes high, equal to 16 pans; the rise is equal to an eighth of the span of the vault's rise.

\section{Analysis in terms of the golden section}

Beginning with the plan of the entire Hôtel de ville it can easily be seen that the whole composition is governed by a golden rectangle whose base is the exterior perimeter of the north facade on Plan de la Cour and whose height the exterior perimeter of the facade on the Rue de l'Hôtel de ville (fig. 5).
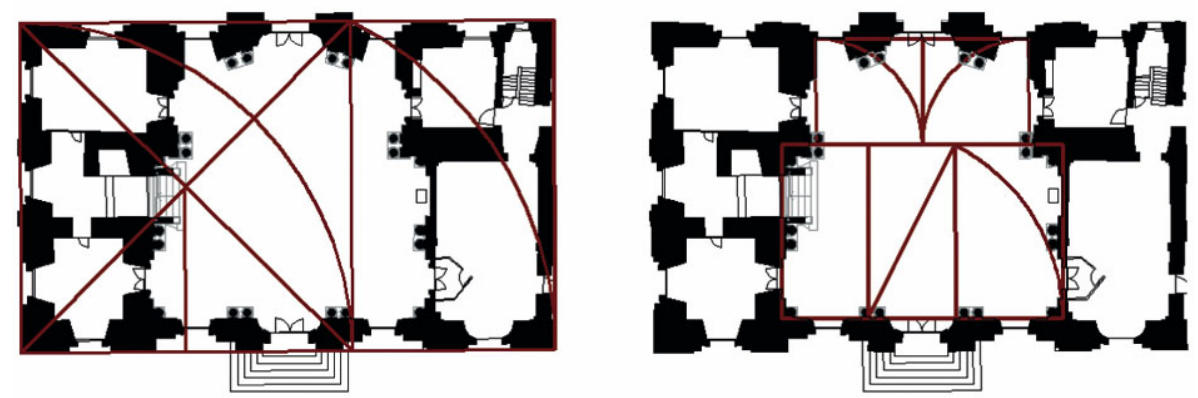

Fig. 5. Analysis of the plan using the golden rectangle 
The golden rectangle is also recognisable in the present-day rear facade. An emblematic characteristic that has emerged from the examination of the elevation is the fact that the rectangle is not immediately legible on the facade on Place de la République: Although a composition based on this rule is credible, an enlargement shows that the perimeters of the facade do not perfectly match the geometry of the golden section (fig. 6). Doubts raised by this incongruence, which is puzzling to say the least and which can lead us to think that this reading is forced, are alleviated by an examination of the rear facade.
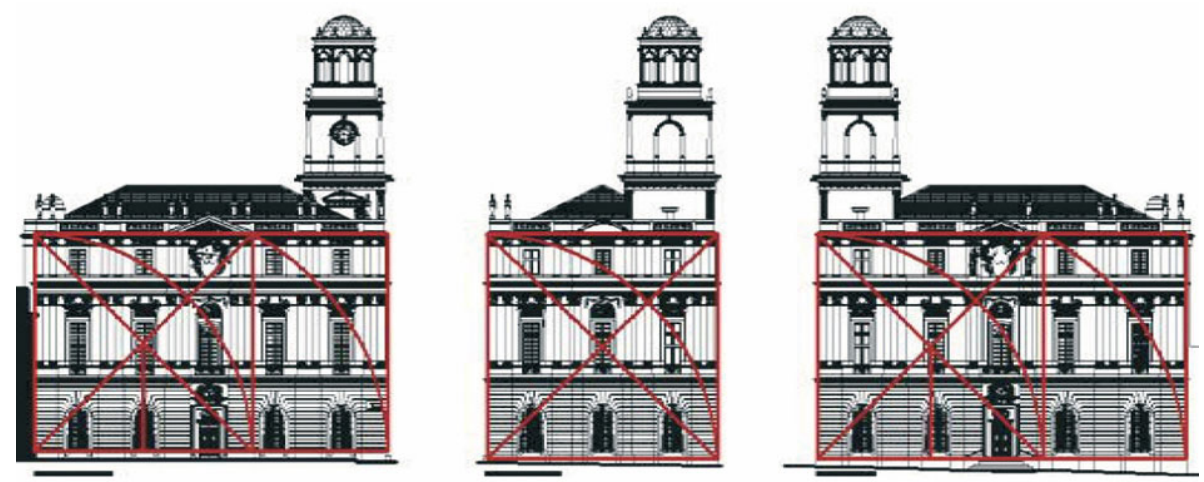

Fig. 6. Analysis of the facades in Place de la République, in rue de l'Hôtel de Ville and in Plan de la Cour, with the golden rectangle or "divine proportion" as described by Fibonacci

The elevation on Plan de la Cour in fact corresponds perfectly to the rigorous construction of the divine proportion. This observation takes on further significance thanks to archival research which has made it possible to understand that the design of the present-day rear facade was originally the main facade designed by the brother of Jules Hardouin-Mansart, Michael. This allows us to understand why the southern facade does not correspond exactly to the golden rectangle. Obviously it is not surprising to associate the elevation on Rue de l'Hôtel de ville with a perfect square. It should be recalled that the ad quadratum method of proportioning, with the square as the figure of reference, was used by architects from ancient times to determine building proportions.

The vault of the Arles Hôtel de ville, and more broadly, all of the vaulted vestibule, fully responds to the Baroque requirement that the entire work must resound with complexity, that it must appear to be the result of an extreme virtuosity, of an illusory appearance, at once exuberant and severely simple, aimed at creating and exalting a state of wonder and marvel.

\section{Analysis of the optical solutions and perspective illusions}

The laws of perspective are used in a way that is the opposite of that of Renaissance art, that is, to multiply rather than unify the points of view.

The spatial arrangement of the interior of the vestibule becomes that much more amazing when it is understood how much attention has been placed on particular observation points. The vision of the entire space changes as the spectator crosses the hall: from the entrance off of Plan de la Cour (fig. 7), looking through the interior vestibule, the capitals placed in front appear exactly straight, in a view that is almost axionometric. 


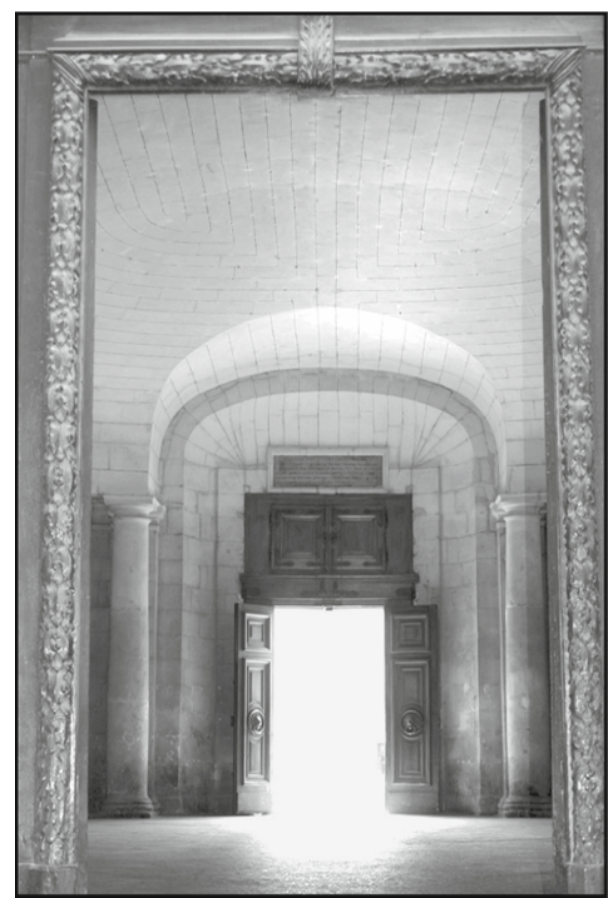

Fig. 7. View into the hall from the entrance of Plan de la Cour, where the column capitals are seen in an axionometric view

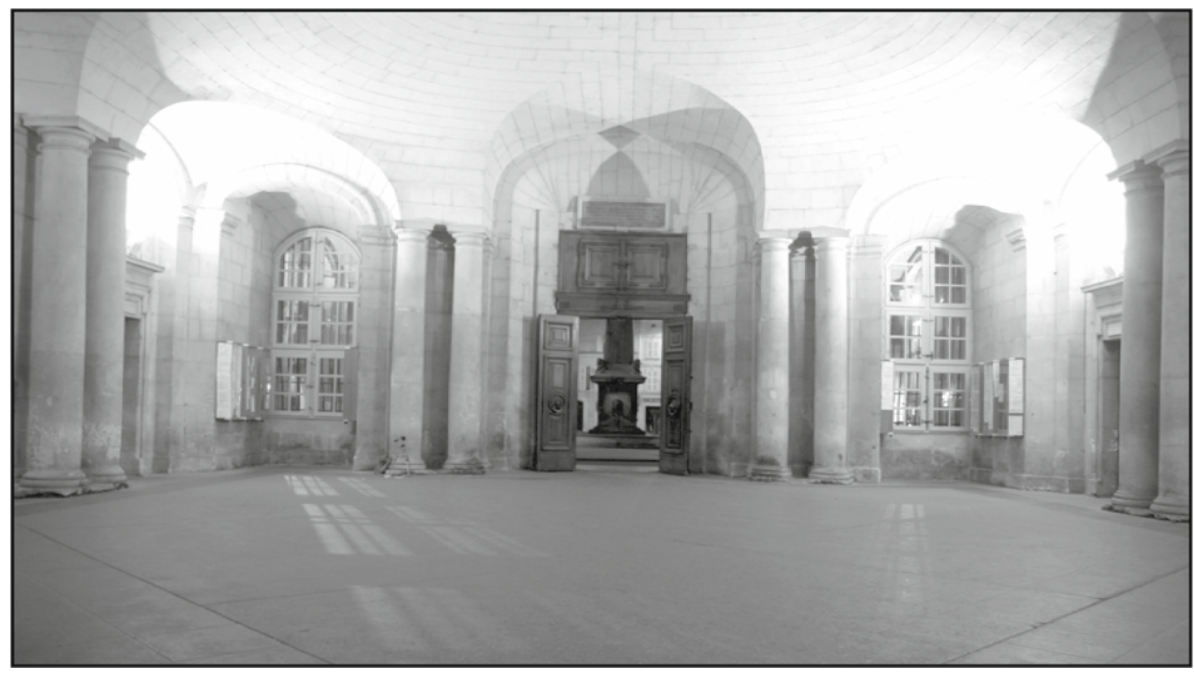

Fig. 8. Perspective view of the capitals of the inner south wall

As one gradually moves from the entrance off of Plan de la Cour towards the entrance off of Place de la Republique, crossing the vestibule longitudinally, the view becomes perspective (fig. 8), until one arrives under the great arch that subdivides the two vaults, where the view shows the capitals to be actually tilted (distorted view) (figs. 9, 10). 


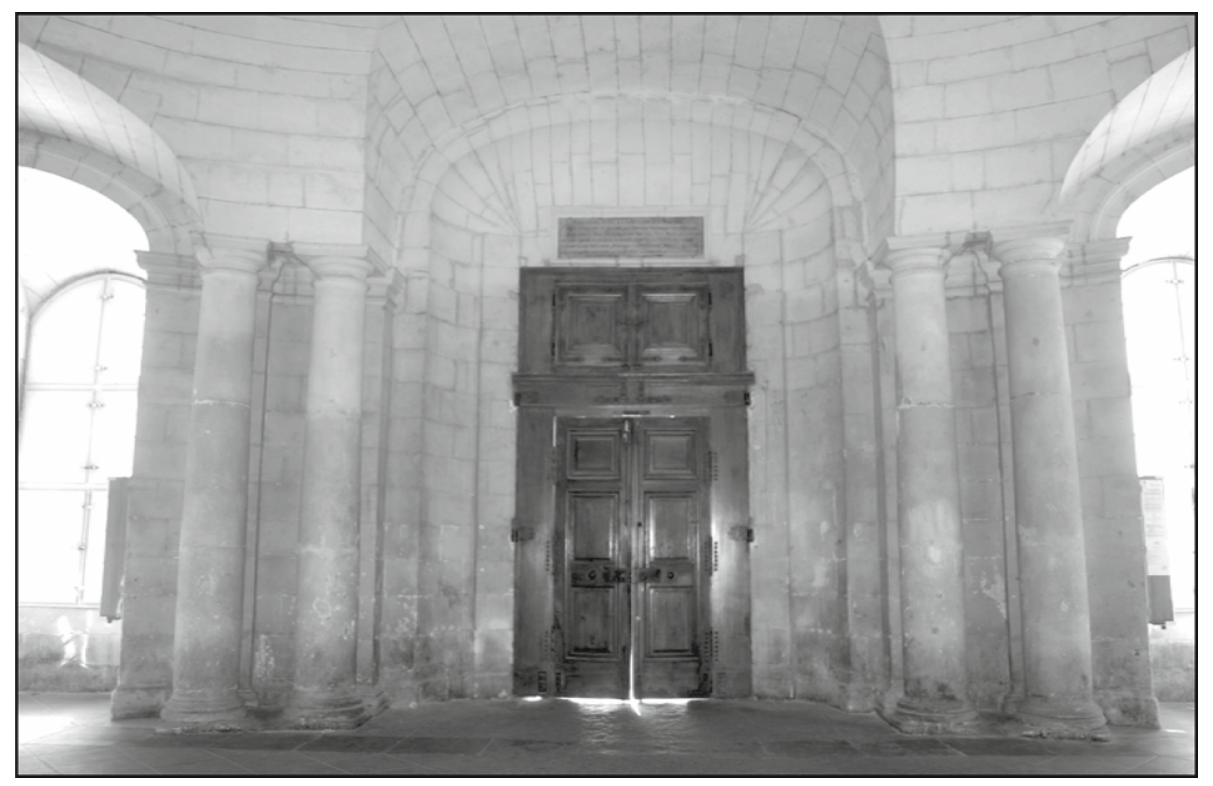

Fig. 9. View of the capitals in showing their actual distorted form

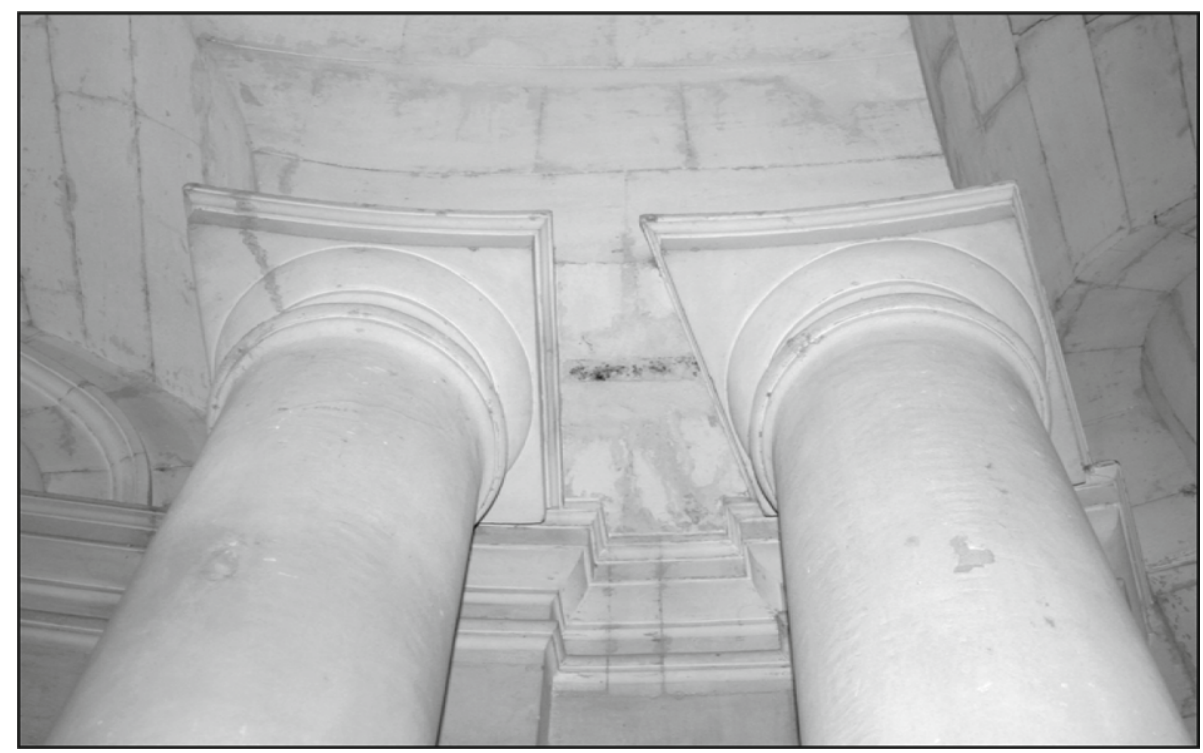

Fig. 10. Close-up of the capitals showing their actual distorted form

The changing way in which the whole composition is viewed as one moves through it, which only occurs when crossing the axis from north to south, confirms the hypothesis that the main facade was originally that located on the north side, in Plan de la Cour. This notion is also supported by the position and shape of the adjacent spaces: the doors of the rooms to the north and south have different dimensions, but on site, the eye is fooled into thinking that they are identical. The survey made of the interior elevations of the vestibule have made evident a notable difference between the doors close to the 
entrance off of Place de la République and those close to Plan de la Cour, of which both the frames and the stone jambs are actually higher and wider. This effectively constitutes an optical strategem so that when the spectator goes down the staircase (fig. 11) or stands under the bust of Mistral (fig. 12) he is presented with a perspective view and the doors appear exactly the same.

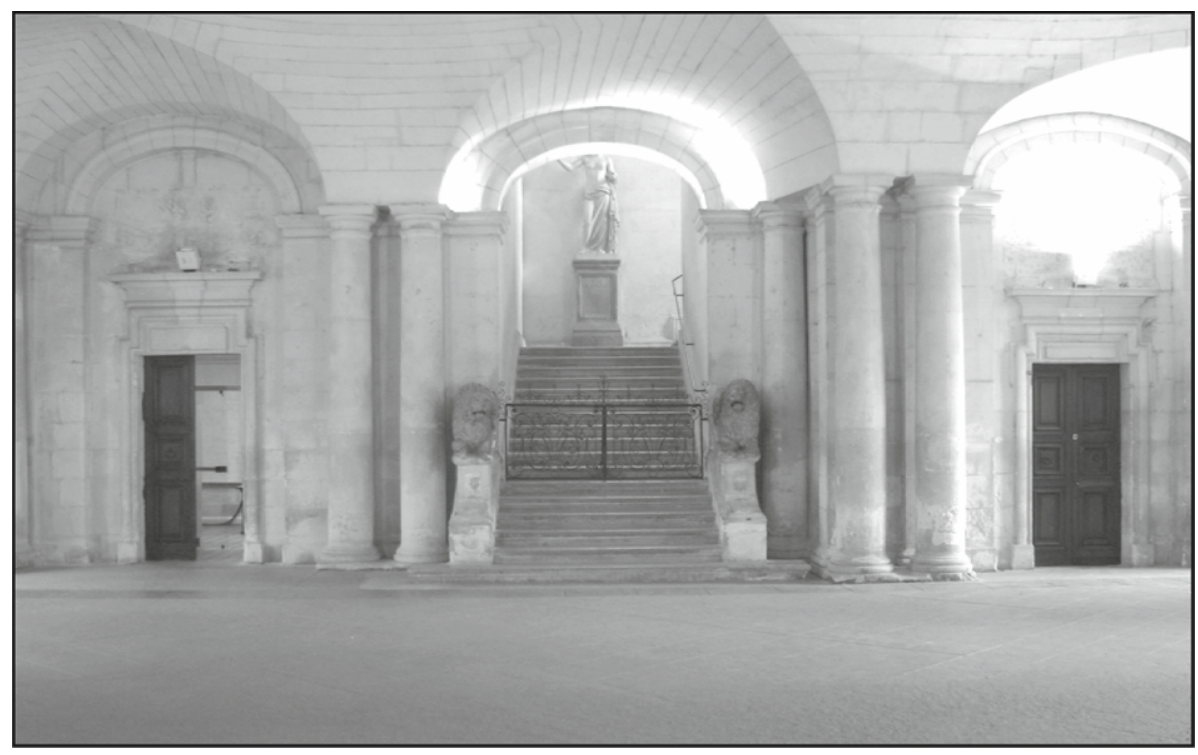

Fig. 11. Interior elevation looking towards the staircase. From this point there is no apparent difference between the doors

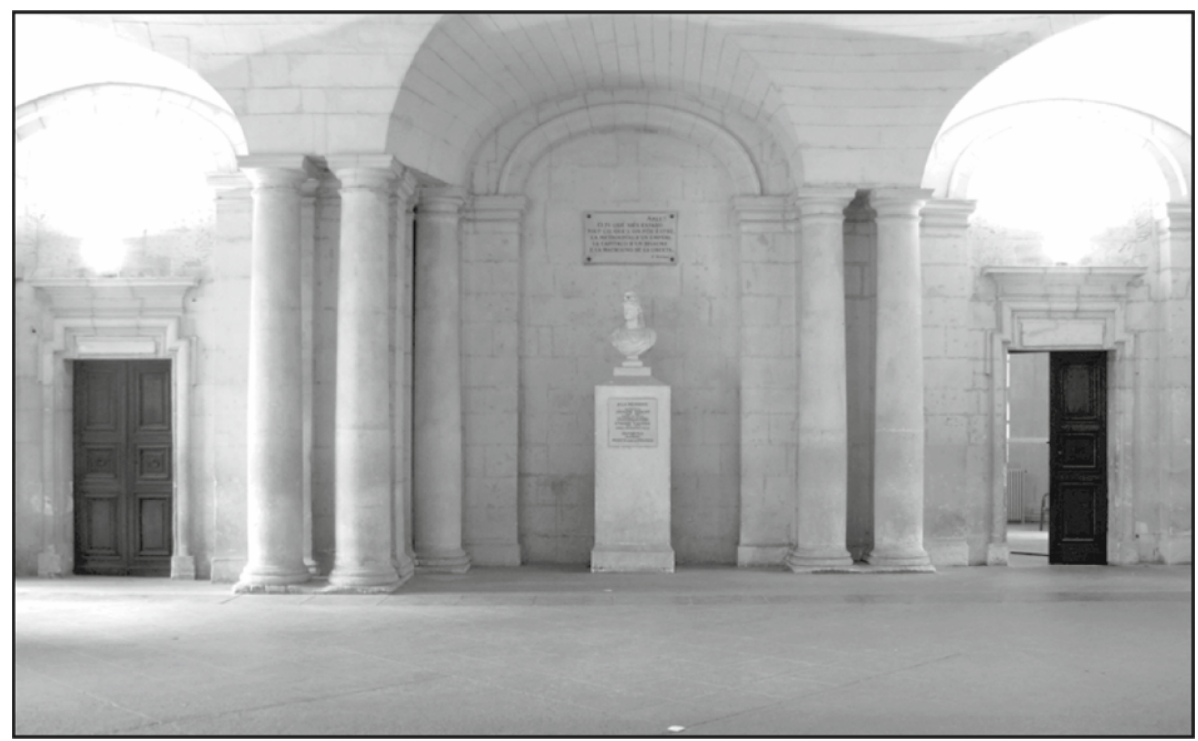

Fig. 12. Interior elevation facing the staircase. From this point there is no apparent difference between the doors 
The aesthetic effect of the vault that Mansart was aiming for was that of making the vaulted space a unicum: all of the horizontals appear continuous and unbroken to the eye of the observer. This effect is heightened thanks to specific aesthetic devices, for example, covering the vertical joints with mortar and emphasising the horizontal joints. The horizontality is also obtained by means of some false grooves that do not follow the way the stone is cut: the eye does not see any kind of discontinuity.

Entering the vestibule from the present-day main entrance off of Place de la République, one has the impression that the hall is much smaller than its sixteen meters, and above all that it is shorter and dilated towards the sides (fig. 13). The flattened arch seems to have a very shallow rise, and to 'fall' heavily on those who cross the southern threshold. The optical effect is due to the continuous horizontality of the joints in the large vault, which gives a sense of 'pressing down'.

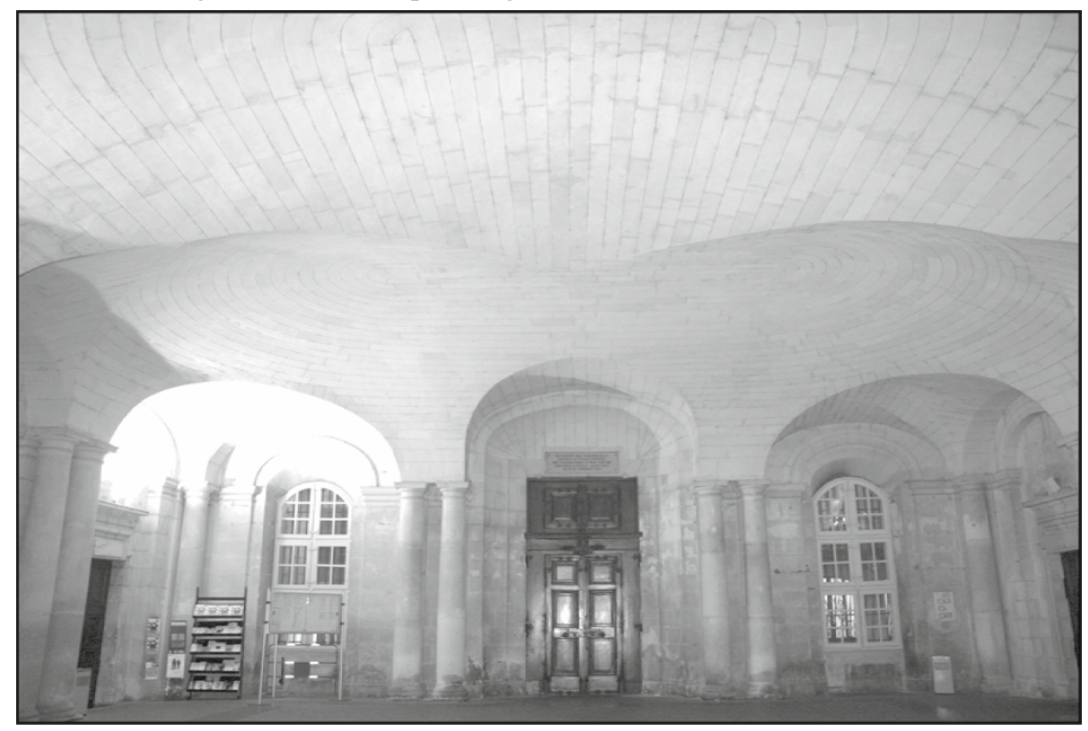

Fig. 13. Seen from the main entrance, the vault seems to have very shallow rises to "fall" heavily on those who pass through the south entrance. The optical effect is due to the continuous horizontal lines on the large vault, which create a strong sense of "crushing"

Entering instead from Plan de la Cour, the former main entrance, the vestibule appears to be dilated, the vault seems to be higher than it actually is, as though it were thrust upwards (fig. 14). This opposite optical effect is made possible by the continuous lines of the central part of the vault, which turn out to be, only in this point, perpendicular to the entrance, giving the idea of straight lines that mark the spectator's path and draw the eye towards infinity. This is an effect that Mansart's work shares with other coeval Baroque creations.

Looking with a critical eye at the portion of the vault that lies over the first steps of the staircase, the ruled surfaces seem to be exactly divided into two clearly distinct parts by the stone that begins at the vertex of the groin, which becomes the keystone, even though it is not in the middle (fig. 15). Looking along the straight line that passes through the vertex of the groin, which separates the two portions of the conoid, it appears that the perspective vanishing point of the line falls exactly on the middle axis of the wall at the end of the stairs, where the statue of Venus is located, while the two conoids could have two different vertices on the axis itself. 


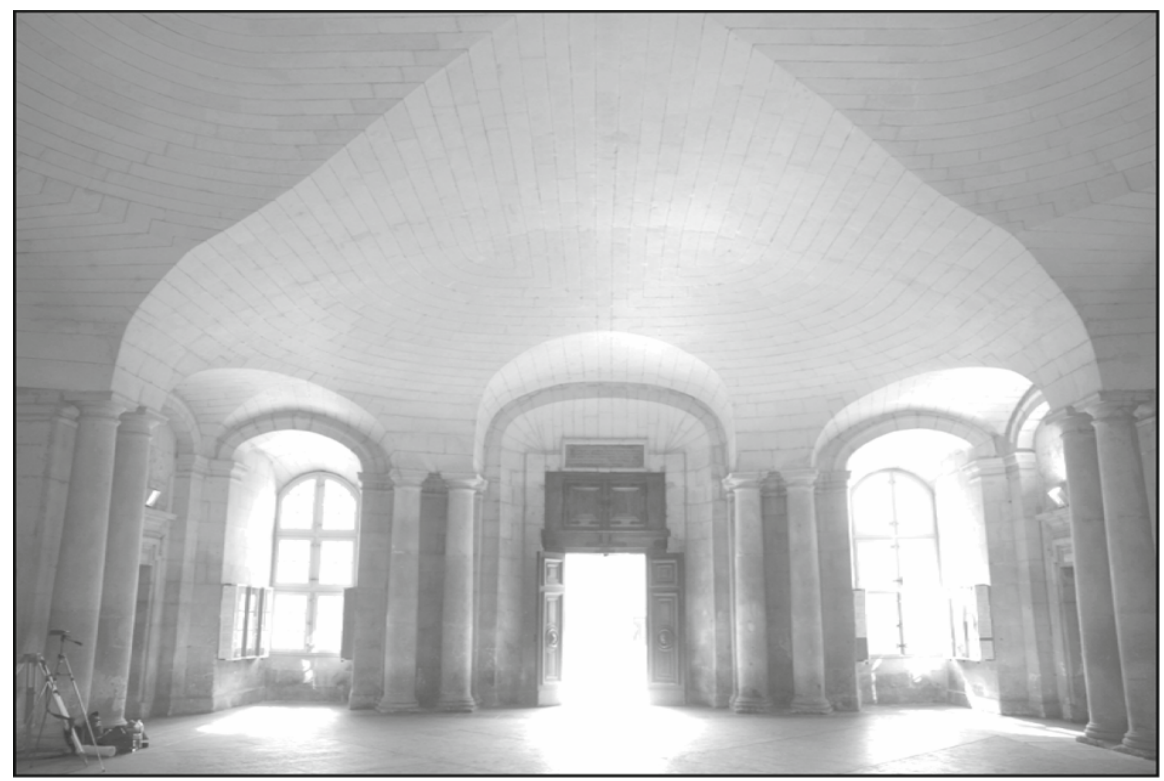

Fig. 14. Entering from Plan de la Cour, the former main entrance, the vestibule is dilated, and the vault seems to be higher than the actual measurement, as though soaring upwards

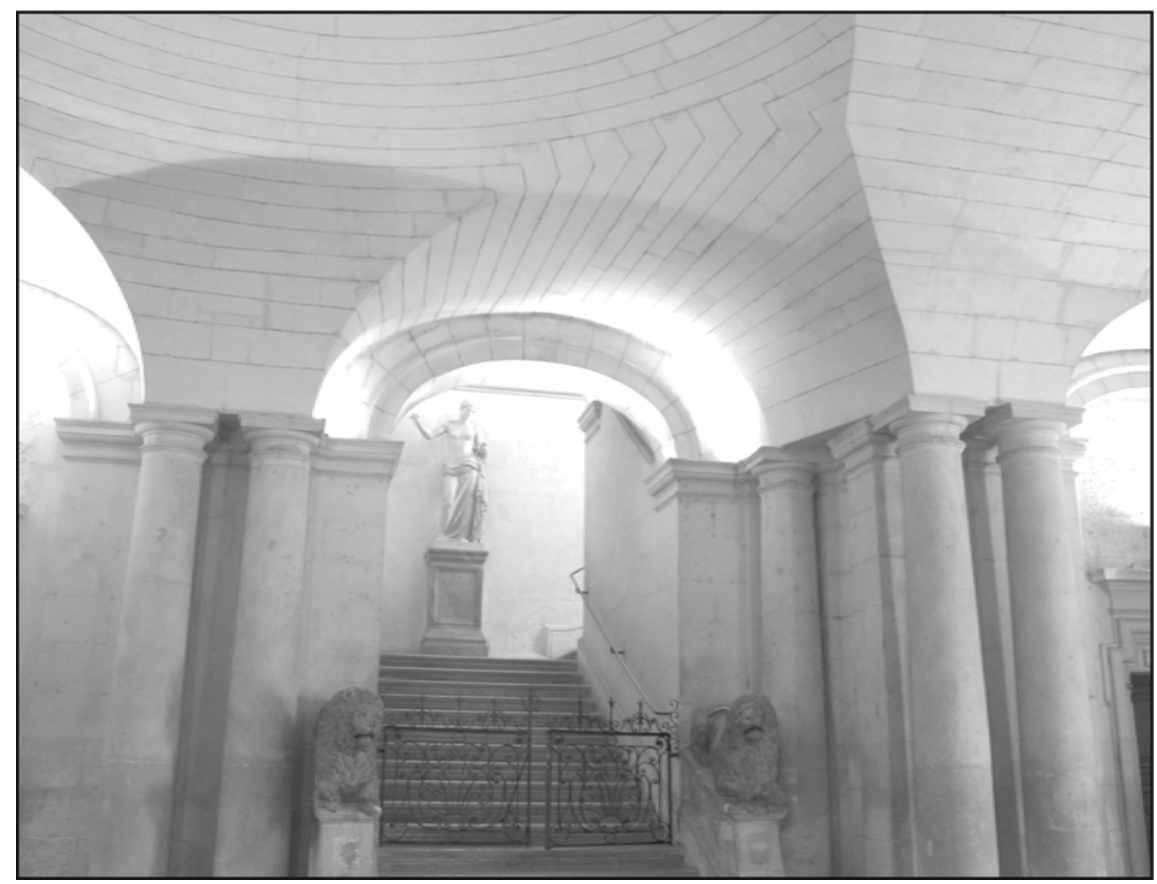

Fig. 15. The striped surface appears to be divided into two different parts from the keystone. Looking along the line passing through this voussoir, which separates the two portions of the conoid, it appears that the point of convergence of the straight lines falls exactly on the median axis of the wall at the bottom of the stairs, where is the statue of Venus is located, while the two conoids could have two different vertices, on the axis itself 
While surveying the base of the statue, we noted a decentralisation of the sculpted point (fig. 16). This supports our geometric theory about the vanishing point, reflecting Mansart's Baroque leanings and sense of scenography. The point is decentralised because it is an intermediate point on the axis.

The reasoning begins with the collocation of the work in the Baroque period, when the upper floor was used as a ballroom. Thus one of the main points of observation of the vault was located precisely on the staircase.

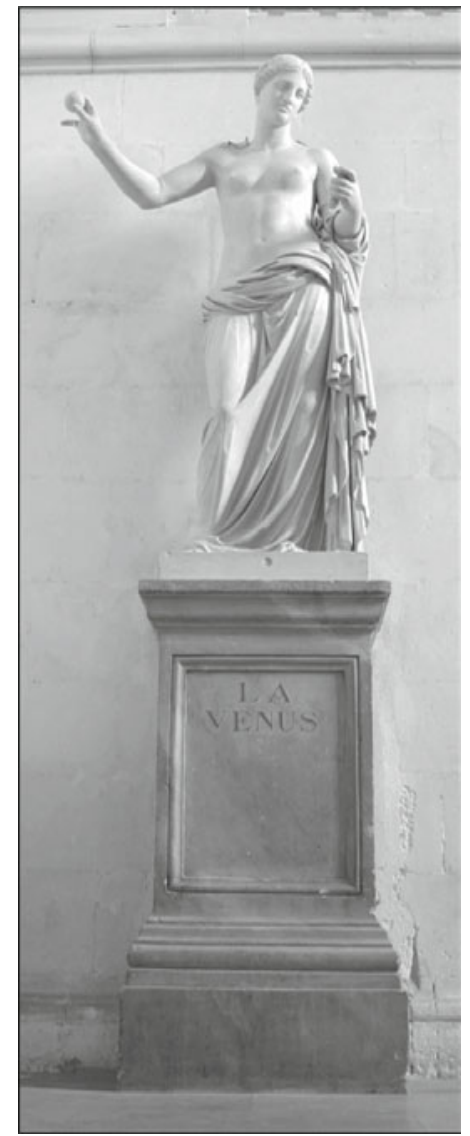

Fig. 16. We noticed on the statue base a decentralization of the sculpted point: this corroborates our theory about the geometric perspective, in defense of the Mansart's Baroque scenocographic aesthetic. The point is decentralized because it's an intermediate point on the axis

The study of light is one of the fundamental characteristics of Baroque architecture. Light assumes an almost paramount importance during this period, and becomes a means for overcoming the static nature of architecture. The desire of the artist was that his work be seen differently according to the various hours of the day or night. Mansart's design goal was that, thanks to the high-quality taille de pierre, stonecutting, used to prepare the stones of the vault in Arles, at 12:00 a glancing light would enter the space, optimum for observing all the edges and spatial arcs of the vault and the material, a stone from Fontvieille, and that the faint glimmering would bring out the stone's true colours (fig. 17). 


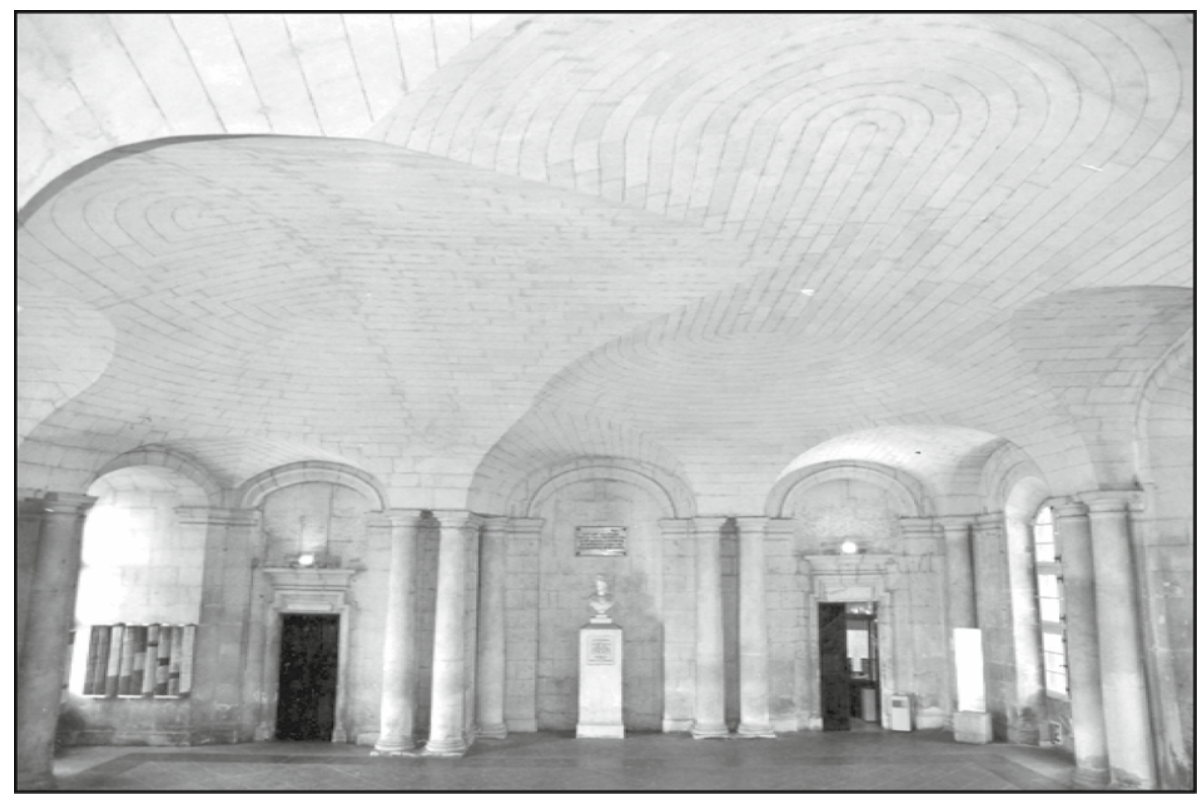

Fig. 17. View of the vault of the hall in the Hôtel de ville of Arles

Our analysis did not end with possible design interpretations, but went on to an examination of the geometry of the surface of the vault.

\section{The survey of the vault of the Hôtel de ville}

The obvious difficulty of measuring the vault - characterised by convex and concave curves, and elements that project and rotate - using tradition survey methods, led to the decision to carry out the entire survey by means of a laser scanner. Other factors which led to that decision were:

- laser technology is essentially unaffected by the motion of passers-by and poor lighting;

- laster technology makes it possible to acquire a large number of points in a uniform manner to define the geometry of the structure without the need to predetermine the elements to be surveyed;

- the acquisition of a dense point cloud makes it possible to construct a threedimensional model and take advantage of innovatiove systems of representation.

The digitalisation was performed by means of the measurements of the positions of a large number of points. The technique of laser scanning, also known as LIDAR (light detection and ranging), is based on the method of measuring the distances by means of electromagnetic waves. In the case of a survey with the laser scanner, there is no possibility of choosing the points to be surveyed, as in general it is only possible to define the area to be measured and the desired density of points. Once these parameters are defined, the acquistion of data is completely automatic. The result of the survey is a point cloud that is quite dense but with a random distribution of points on the object. 


\section{Editing the point cloud obtained by the laser scanner}

Once the data has been obtained by the laser scanner (the point cloud), it is necessary to proceed to the elaboration of the information obtained. The first step is the careful creation of a mesh that will guarantee the required level of precision and detail. The specific software for elaborating the data includes commands for regulating the maximum number of triangles or the minimum distance between adjacent points. However, these tools must be used with caution, because while on the one hand they help to eliminate data that is redundant, on the other there also exists the risk of eliminating information in places where redundant information is helpful. Once created, the mesh must be checked for holes, which can subsequently be minimised or eliminated.

It is possible to derive a series of sections directly from the point cloud obtained from the survey: in our case, twelve such sections were derived in the vertical plane, while fiftytwo were derived in the horizontal plane. The sections were organised into small groups, and once detailed editing was performed on each, it was possible to import into a new file all the reworked, reformatted sections that had been chosen for the creation of the final model.

As mentioned, the point cloud had been sectioned by fifty-two horizontal planes and twelve vertical planes. The fifty-two horizontal planes were perpendicular to the vertical of the laser scanner, that is, orthogonal with respect to the $z$-axis of the global reference (fig. 18). This established the contour lines of the vault; these were useful for the subsequent analysis of the vault's deformations and geometry.

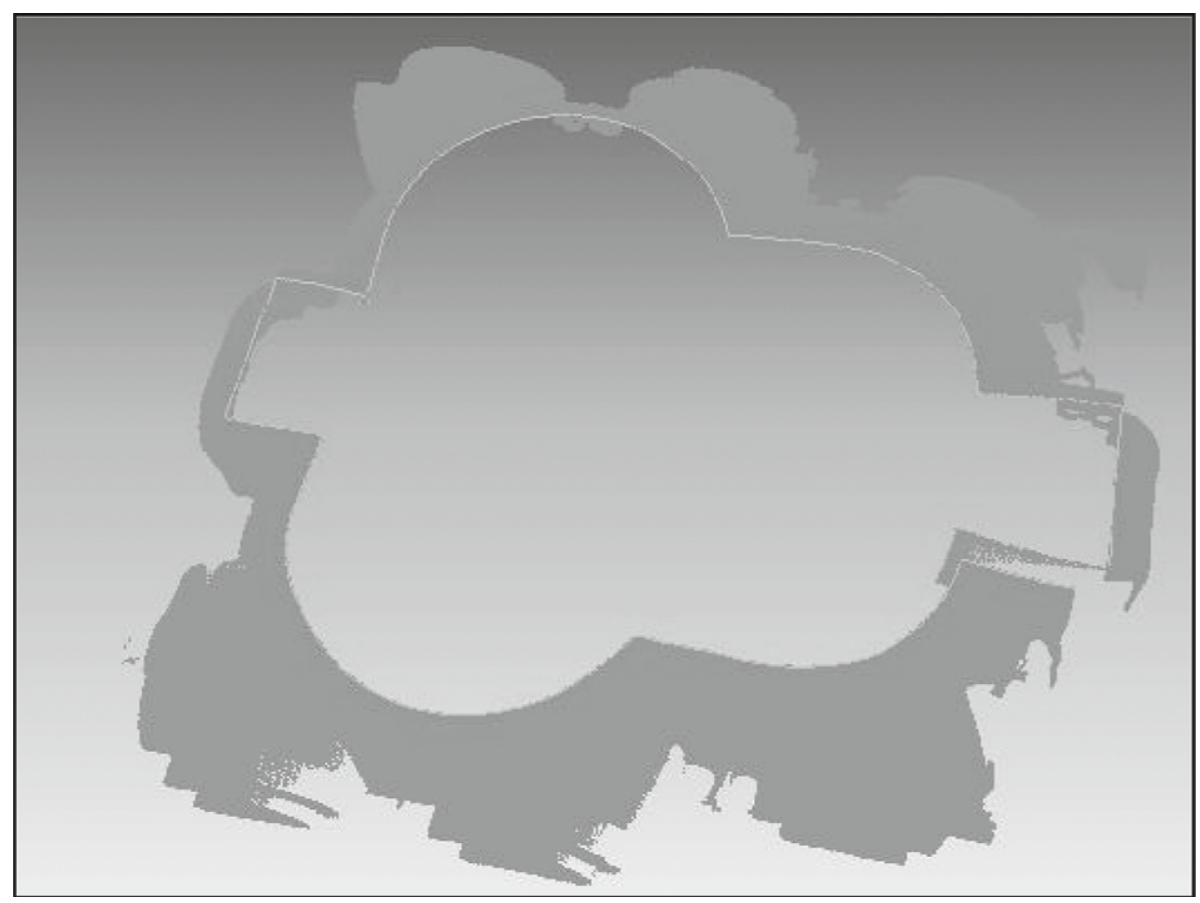

Fig. 18. Horizontal section obtained from the points cloud 


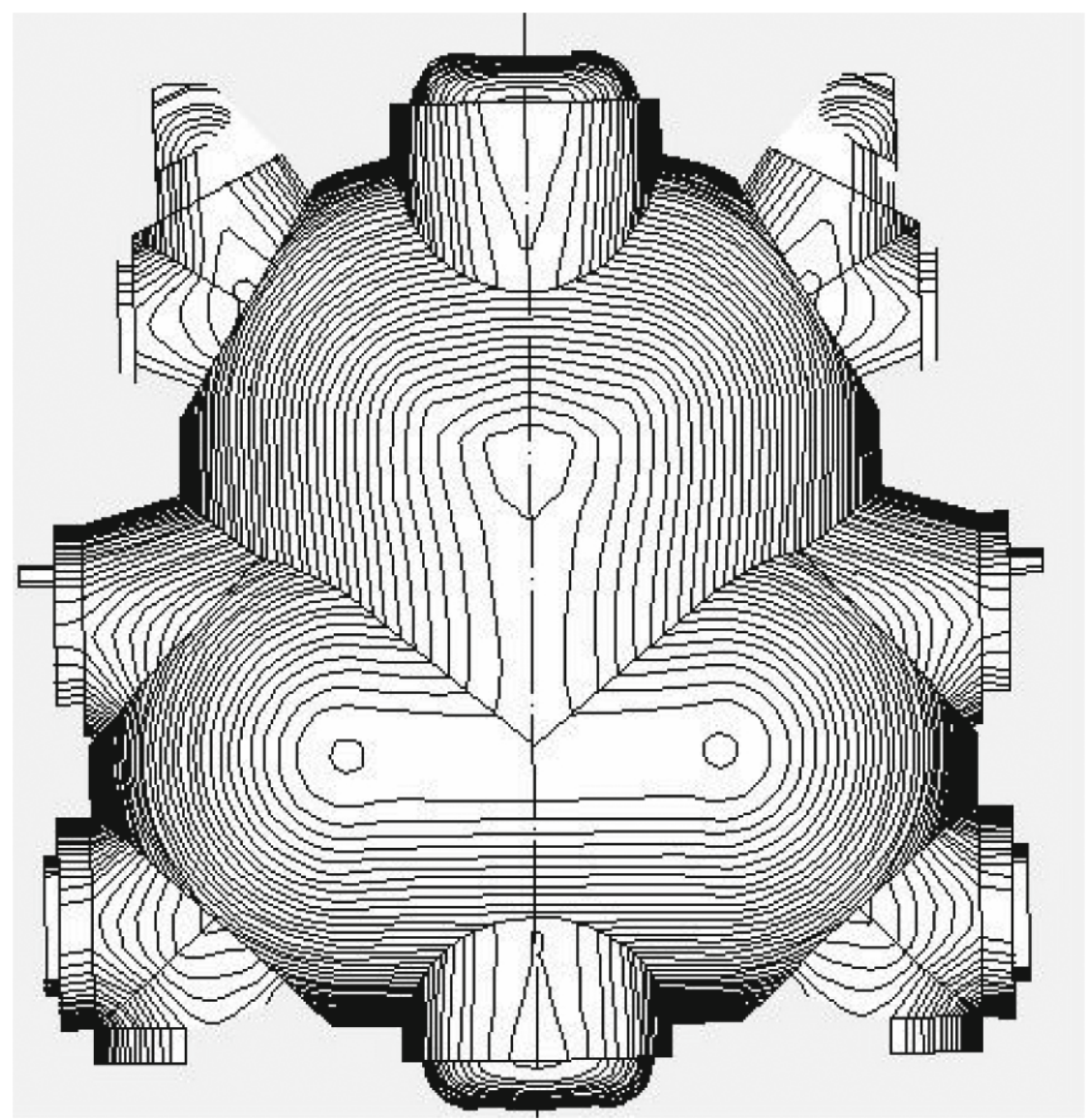

Fig. 19. Horizontal sections which shows the real surface of the vault

The contour lines made it possible to see that the vault showed a slight sag due to settlement of the cylindrical vault generated by the large arch. The directrixes of a cylindrical surface are parallel lines, whereas the directrixes of the started out parallel at the base of the vault and began to converge close to the apex (fig. 19). The subsequent flattening of the vault is in any case quite small (on the order of a tenth of a centimeter). This result confirmed the decision to carry out the survey by means of the laser scanner; no manual survey could possibly have made such a small deviation evident.

The twelve longitudinal sections were derived with planes parallel to the $x-y$ - and $y-z-$ axes of the global reference system. These planes allowed us to define the shapes of the vault's surface (fig. 20). At this point we deduced that the vault is actually composed of five different types of vaults: two barrel vaults and anse de panier, or basket handle shaped, lunettes. The main barrel vault is terminated at each end with two hemispherical vaults (cul de four) and is intersected by a second, transversal barrel vault, which in its turn terminates in a large lunette. We thus have four lunettes at the center of each side and four double lunettes in the corners. 


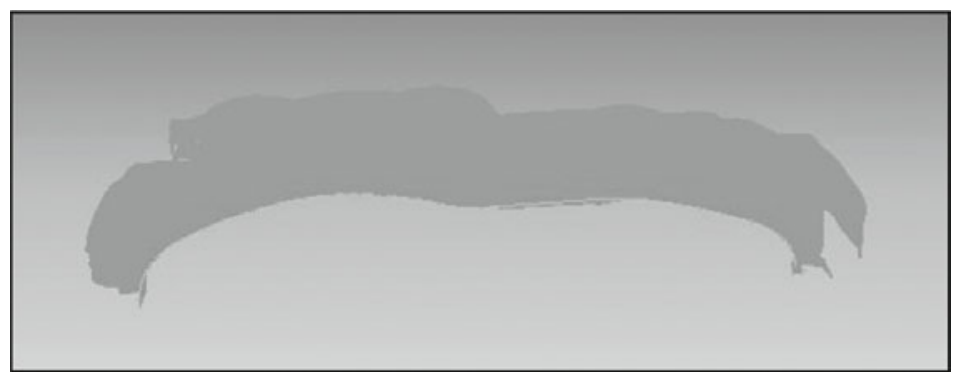

Fig. 20. Vertical section obtained from the points cloud

The elaboration of the point cloud led to the creation of three models: a model of the existing vault obtained from the mesh created from the cloud point obtained; a geometrical model that approximates the existing situation; and a theoretical geometrical model that unites the information gleaned from documentary sources with that of the theoretical geometrical model.

The methodology adopted consisted of three phases: careful examination of the threedimensional model of the point cloud; a geometrical analysis of each individual curve; the formulation of a hypothetical geometrical model.

The analysis of the three-dimensional model obtained by the survey was made by taking horizontal sections of the point cloud every $5 \mathrm{~cm}$ starting at the (horizontal) plane of the vault's impost. The sequence of points obtained with each section was reinterpreted by vectorization.

\section{Geometric analysis}

The drawing of the contour lines represents the deformation of the surface of the vault that resulted from the loads to which it was subject over the course of time. Thus, in the attempt to formulate a hypothetical geometrical model of the surface as it was originally conceived by Mansart, certain criteria were established for interpreting the deformity:

- the curves interpreted as series of concentric arches identify a surface of revolution; geometrical elements characterised by very slight curvatures are interpreted as straight lines (curved as a result of deformation);

- curves classified as conics represent sections of quadric surfaces.

As a result of the analysis based on these criteria, the curves that were determinant for the creation of the model in question (that is, the directrixes and the generatrices) were identified (figs. 21, 22). These curves were derived when horizontal and vertical sections of the point cloud were studied individually from the point of view of geometry.

The intrados as a whole is comprised of three types of surfaces:

- $\quad$ surfaces of revolution (end portions of the small vault);

- quadric surfaces: extruded solids, where the generatrices are circular segments and the directrix is a horizontal line (central portions of the small and large vaults, central groin between the two vaults, lunettes over the entral portals); ellipsoids (end portions of the large vault); 
- 2-rail sweep surfaces with one directrix (double corner lunettes, central lunettes, triangular connecting surface in the small vault).

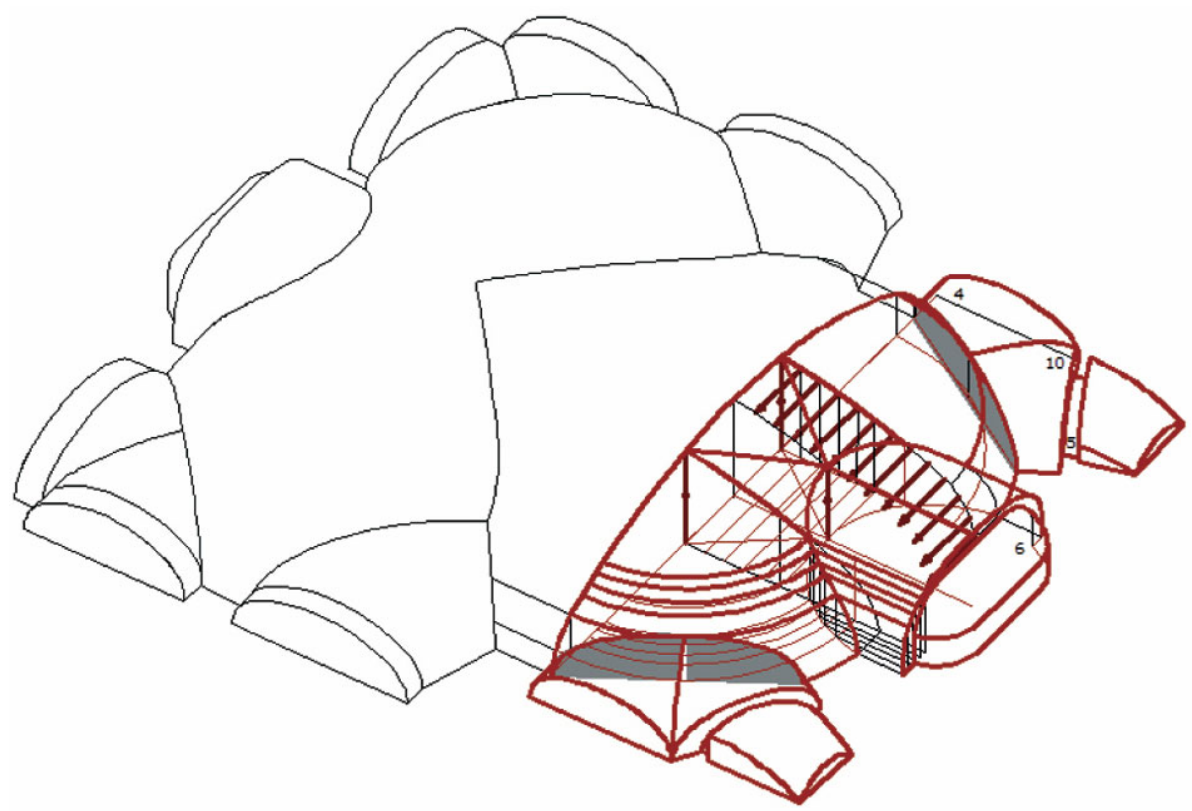

Fig. 21. Drawing of the theorical geometry model

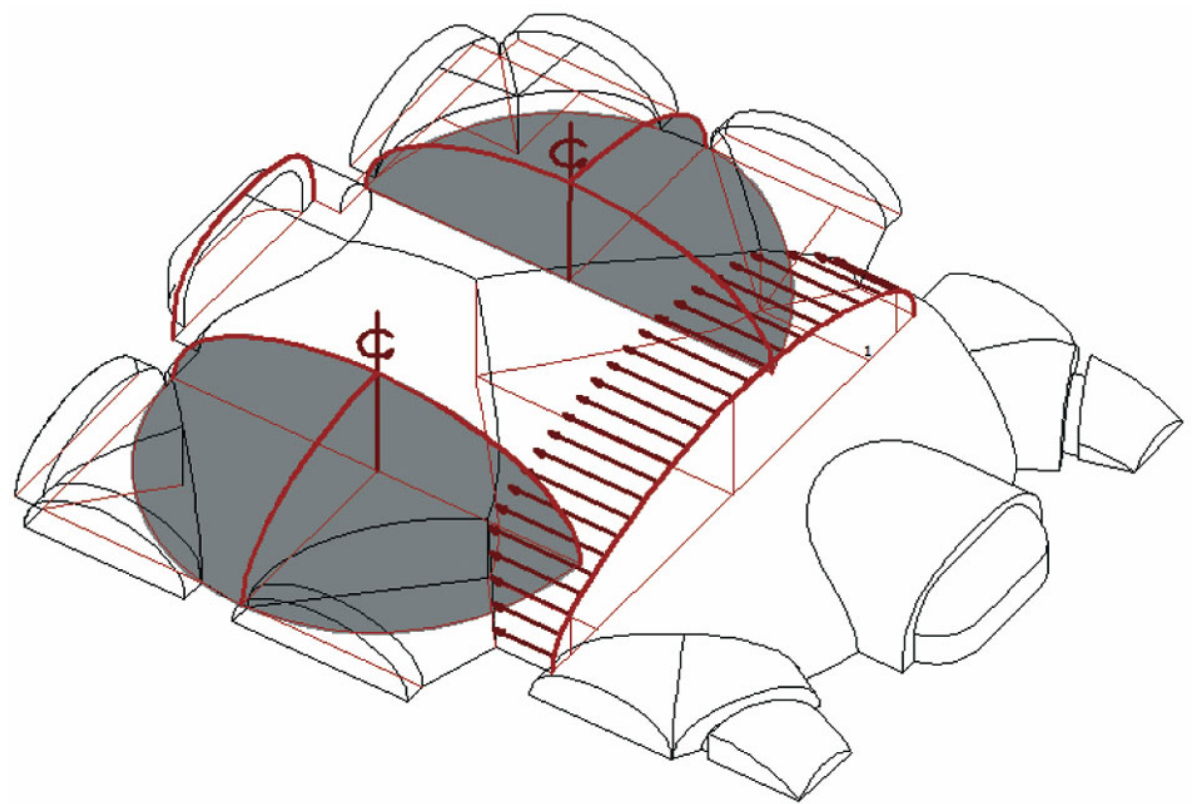

Fig. 22. Drawing of the theorical geometry model 
The definitive geometric model is composed of various parts:

- the large arch;

- the small vault;

- the large vault;

- the groin between the large and small vault;

- the double corner lunettes and the central lunettes;

- the lunettes over the north and south entrance portals.

The small vault is the result of four segments of surfaces obtained in this way: the identification of the large arch and on it, two segments that constitute the profiles that generate the two surfaces of revolution about the $z$-axis; the extrusion along a straight line generatirix of the profile that results from the revolution; the horizontal extrusion of the arch of the south entrance portal.

Two elements are obtained by these operations: 1) a space curve that is the intersection of the last two surfaces mentioned; 2) a triangular surface connecting the point of the apex of that curve and that of the large arch.

The large vault is given by the sum of the two quarter-ellipsoids and a surface obtained by extrusion along a horizontal straight line of the profile derived from a vertial section of the ellipsoid.

In this case as well a second intersecting space curve is created between the lunette of the north entrance (derived in the same way as the lunette of the south entrance mentioned earlier) and the surface of the large vault itself.

The intermediate lunette between the large and small vaults is the result of a horizontal extrusion of the large arch. Instead, the surfaces of the corner and central lunettes are obtained as 2-rail sweep surfaces with one directrix.

In the final analysis, from the intersection of all the surfaces that compose the vault as a whole, we obtain various kinds of edges:

- vertical plane curves (from the intersection of the large or small vault with the corner lunettes, from the intersection of each pair of corner lunettes, and from the intersection of the large and small vaults);

- space curves.

The following working hypotheses were formuated:

- $\quad$ the vault was considered symmetrical, thus only one part was analysed;

- vertical and horizontal sections were taken from the point cloud, at exactly the coordinates through which planes that were believed to belong to curves considered generatrices or directrixes of the vault passed;

- the curves determined by the survey were compared to those obtained by the theoretical model.

In addition to this kind of approach, which compares and contrasts the theoretical model with that based on the point cloud, it is possible to perform critical analyses that originate in the geometrical study made of each curve. To this end, the curves of the vault can be grouped into the following categories: the diagonal curves that separate the large and small vault from the corner and central lunettes; the curves of intersection 
between each pair of corner lunettes; the curves on the east and west walls; the curves on the north and south entrance portals; the curves adjacent to the north and south entrance portals. All of these curves are polycentric, constituted of from two to five circular segments. The geometric methods we used to draw the curves were:

- the method of Abraham Bosse, which is equivalent to applying Archimedes' lemma 3;

- $\quad$ the method of Christiaan Huygens.

Bosse's method is valid for the construction of arches with two or three centres that are symmetrical with respect to the vertical axis. Huygens's method is valid for any number of centres and can be used for both symmetrical and asymmetrical constructions. It was used for the construction of curves with four or five centres. In light of this it can be stated that the diagonal curves belonging to the first category have five centres, symmetrical with respect to the vertical axis, drawn using the method of Huygens's, beginning with a semi-decagon.

Two of the three curves on the east and west walls have three centres, symmetrical with respect to the vertical axis. These were drawn using Bosse's method (that is, by applying Archimedes' third lemma). The last curve, the central one, showed different characteristics: it has four centres, is asymmetrical, and was constructed using Huygen's method.

The curves of intersection between each pair of corner lunettes have two centres, and were drawn using Bosse's method.

The arches of the entrance portals consist in a polycentric curve and two line segments. In particular, the curve of the north entrance has three centres, is symmetrical with respect to the vertical axis, and was drawn using Huygens's method; however, it was not based on a regular polygon, but rather on one of angles $65^{\circ}, 25^{\circ}, 25^{\circ}, 65^{\circ}$.

In contrast, the curve of the south entrance has five centres, is symmetrical with respect to the vertical axis, and was also constructed by Huygens's method, but beginning from the half-decagon.

The curve adjacent to the north entrance has five centres, is symmetrical, and was constructed using Huygen's method, based on the semi-decagon, whereas the curve adjacent to the south entrance has four centres and is not symmetrical, but rather corresponds to angles $45^{\circ}, 45^{\circ}, 32^{\circ}, 58^{\circ}$.

The large arch is a case all of its own. It is the principal element of the vault and can be looked at from three points of view: compositional, constructive and geometric. In terms of composition it defines the space covered by the two vaults. In terms of construction it supports the loads that derive partly from the large vault, and partly from the small. Geometrically it is a three-centred curve.

With regard to the large vault, the two vertical generatrix sections are segments of a single oval. Instead, with regard to the small vault, a series of horizontal and vertical sections taken from the point cloud made it possible to obtain useful information:

- the oblique side of the connecting triangular surface turns out to be parallel to the straight line that is the projection in plan of the diagonal arch of the southeast lunette;

- the small vault is comprised of three parts, of which two are surfaces of revolution and one of extrusion. 
Having modelled the surface of the intradox of the vault, the next step was to draw the lines that make up the stereotomic pattern. Particular attention was given to the longitudinal lines that provide the design of the intrados with its continuity, in accordance with Mansart's aesthetic objectives.

The reconstruction of the pattern began with the identification of the blocks of the large arch, using the studies made available to us by Luc Tamboréro, carried out in 1996 on the small vault. Horizontal planes were made to pass through the points identified by the joints of the blocks. The sections cut through the small and large vaults by these planes generated the pattern of the lines on which the two vaults were based.

A different method was used to discover the device used for the double corner lunettes and the central lunettes. In this case the process used was that of the rectification of photographic images of each arch on the wall, from which the pattern of the joints was obtained. Connecting the points of the joints thus obtained with those deriving from the planes of the horizontal sections made it possible to identify the stereotomic pattern.

As we said earlier, the vault was not conceived as an assembly of several surfaces, but rather as a single, complex structure. The unitary nature of the vault is due to the presence of the lines that mask the actual surfaces of the intrados, making those parts simpler and thus capable of being related to cylinders or spheres.

\section{A different analysis by Luc Tamboréro (Compagnon du Devoir)}

A separate analysis of the vault was made by Luc Tamboréro, nicknamed Perséverance of Arles, who, in 2001, built a stone model of the small vault at a scale of $1: 5$, in accordance with the principles of seventeenth-century stereotomy; it was the final work of his studies with the Compagnons du Devoir.

The working method adopted was principally based on historic study of the archives, a precise survey and the creation of a model on a scale of 1:5, in Fontvieille stone.

The construction of the vault was based on three points:

- $\quad$ the governing lay out;

- the dual role of the plan view;

- stereotomy and its methods.

\section{The governing layout}

Two interpretative frameworks are superimposed on the setting up of the vault. The first one is linked to the module of the canne. For instance (fig. 23), the base square is 8 cannes $(16.37 \mathrm{~m})$ long on the side, and the columns for the north and south walls are regularly spaced with regard to this unit of measurement (fig. 24).

The second framework concerns the construction of the regular pentagon using straightedge and compass whose opening is set only once and remains fixed in the course of the construction, given by Dürer (see figs. 23 to 25 ).

This makes it possible to determine the positions of the east and west columns, of the key stones and of the centering point, as well as the position of the penetrations and even the rises of the arches, as we will demonstrate below. The second implementations are, of course, incommensurate with the canne. 

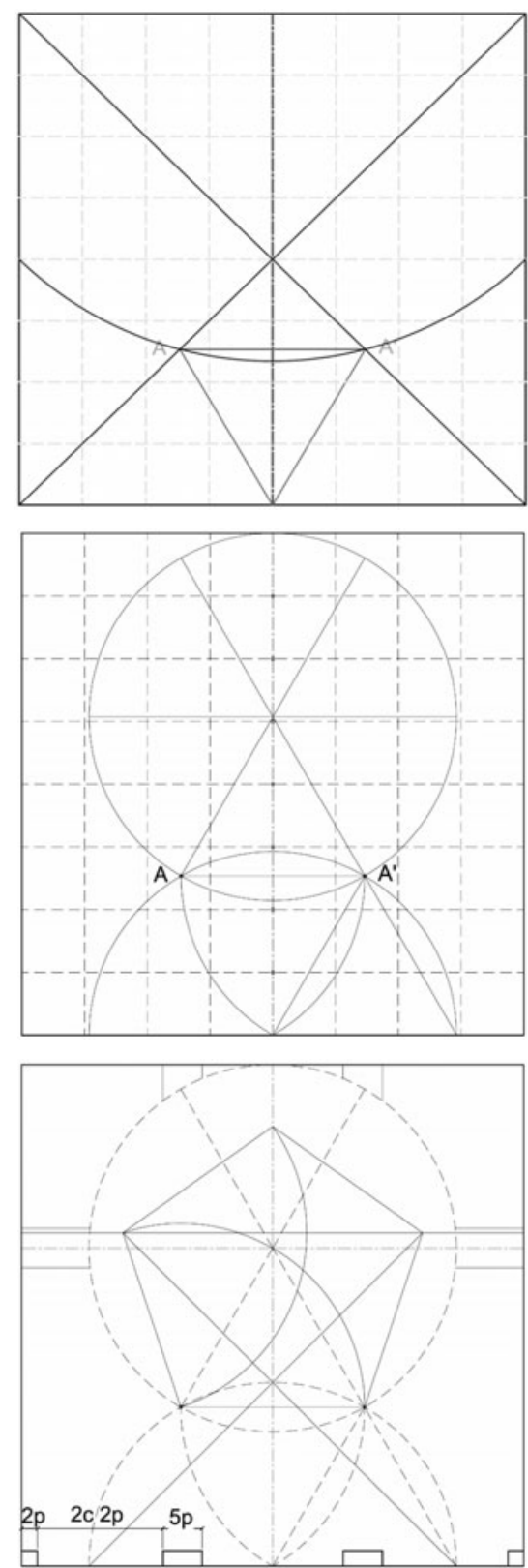

Fig. 23. Drawing of a circle and semi-circle, intersecting according to a bowstring equal to their common radius. The point $\mathrm{A}$ and $\mathrm{A}^{\prime}$ will be the horizontal projections of he keys of the large vault semidomes

Fig. 24. Drawing of a circle and semi-circle, intersecting according to a bowstring equal to their common radius. The point $\mathrm{A}$ and $\mathrm{A}^{\prime}$ will be the horizontal projections of the keys of the large vault semidomes

Fig. 25. Construction of the regular pentagon using straightedge and compass whose opening is set only once and remains fixed in the course of the construction, given by Dürer, (the side of the pentagon is the radius of the circle of fig. 23)

The drawing of the North-East and North-West double lunettes clearly confirms the existence of these two frameworks. Indeed, the axial edge, for example, of the North-East lunette joins midpoint 2 of the penetration edge with point 1 (see fig. 28). The drawing is based partly on the modular drawing and partly on the pentagonal drawing, is therefore not orthogonal to the penetration edge. This remark proves that the governing drawing has been scrupulously followed. 


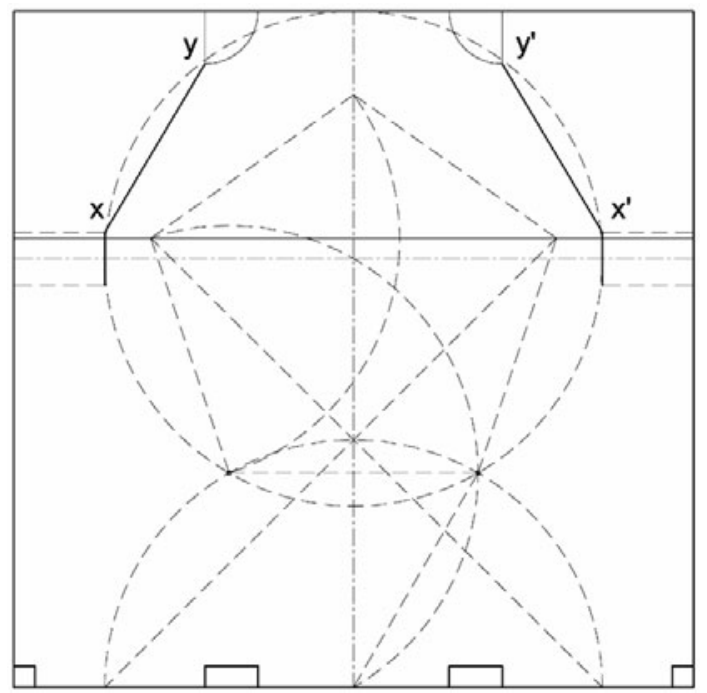

Fig. 26. The two segments $x, y$ and $x^{\prime} y^{\prime}$ are not layout of the penetrations of the two double lunettes in the semidomes of the small vault. This drawing was obtained from a modular North-South layout and from a pentagonal East-West layout

\section{The dual role of the plan view and the volume defined according to the penetrations}

One of the principles of constructing the drawing apparently lies in the establishment of the horizontal projections of the penetrations. The penetrations of the large and small vault with the double lunettes are flat; that of the two main vaults is partially flat; those of the entrance lunettes with the principal vaults are circular (horizontal projection) (see fig. 29).

We chose to work on the small vault, its construction principle being identical to the large one. Once the plan implementation had been determined, the penetration edges between the vault and the lunettes were drawn on this very same projection. These edges, which are basket-handles curves with five centers whose span is given, have been drawn following the method of Christiaan Huygens. But contrary to Huygens, who considers the rise as given and chooses the first centering point, Mansart gave himself the two centering points (one of which is point a) and deduced the rise from those (see fig. 28). All plan, penetrations or outline arches are basket-handles with five centers, drawn according to the same method. Only the large arch which support the partition wall and on which the two vaults rest, is a connection arch with three centers. Moreover, the global drawing is based on a template shape arch included in the vertical plan bH. The distance $\mathrm{bH}$ being unequal to the distance $\mathrm{bK}$, the two arches are different. But whereas a regular distortion from bK to bH would have produced horizontal joints, Mansart chose two different connecting curves which generate the bending of the intrados.

The order of the drawing and of the construction is therefore as follows:

- the periphery arches and the double lunettes;

- the large arch;

- $\quad$ the small vault with the large entrance lunette;

- the large vault. 
The archives also confirm this order.

The rest of the drawing (see figs. 27 and 28) will be obtained by lines between the horizontal projection and the points, on this view of the different arches.

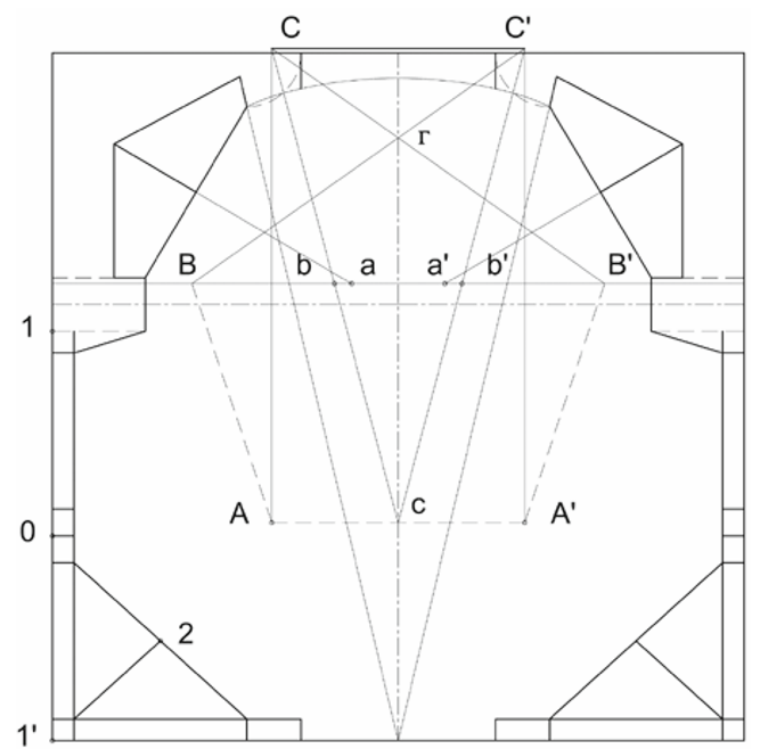

Fig. 27. The segment $\mathrm{Br}$ and $\mathrm{B}^{\prime} \mathrm{r}$ of the pentagon are extended until they intersect ( $\mathrm{C}$ and $\mathrm{C}^{\prime}$ ) with straight line of the spacing $\mathrm{AA}^{\prime}$. The segment $\mathrm{CC}^{\prime}$ is located at $10 \mathrm{~cm}$ above the base square according to the regulator drawing, $3 \mathrm{~cm}$ according to the tracing; taking into account the encounter angle and the number of previous operations, the mistake in minor. From $c$, in the middle of $\mathrm{AA}^{\prime}$, we draw $\mathrm{cC}$ and $\mathrm{cC}^{\prime}$ with cut $\mathrm{BB}^{\prime}$ respectively at $\mathrm{b}$ and $\mathrm{b}^{\prime \prime}$. The point $\mathrm{a}$ and $\mathrm{b}$ will be the centering points of future drawing. The point 0 , which positions a pair of columns, is the middle of segment $1,1^{\prime}$ and does not belong to the straight line $\mathrm{AA}^{\prime}$.

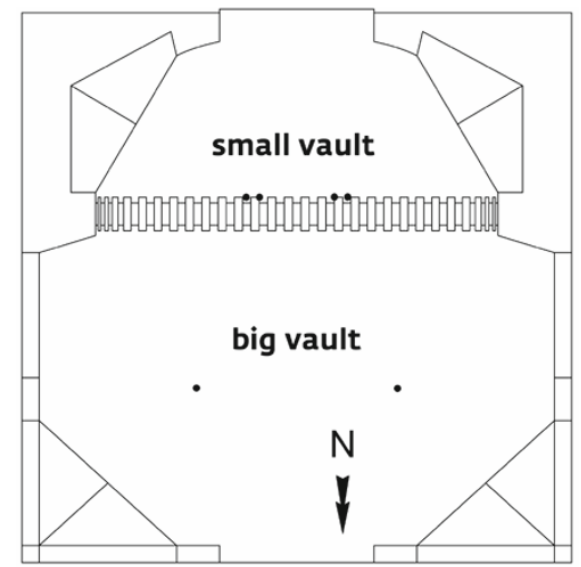

Fig. 28. Schematic of the vault of the vestibule with the subdivision of small and big vaults by the great arch 


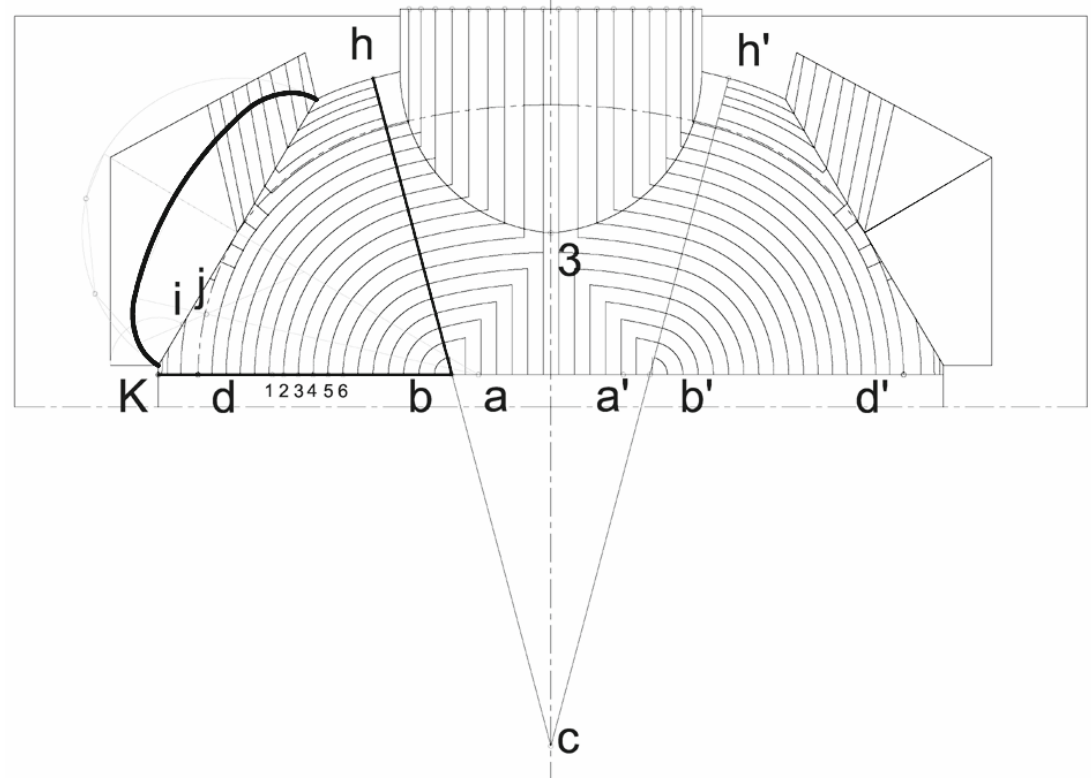

Fig. 29. Schematic detail of the small vault

As the penetration arches for the vault and the lunettes have already been determined, the drawing of the large arch and the drawing of the template shape arch bH are deduced from them (and not the contrary). The five centering points $a, a^{\prime}, b, b^{\prime}$, c, enable one first of all to draw the curve $\left(d-d^{\prime}\right)$, tangent to the lunettes. Center a is used for transferring the shape of arch I to the cross wall; center $b$ is used for transferring the shape of the arch I to the template arch bH. It is the distortion of the crosswall springing curves which confirms that the order which is followed is indeed the one which has been described. This arch is composed of two distortion curves and a connecting arch which is the only one divided regularly into forty-five modules. These modules will generate the disposition of the joints on the small and the large arches.

As the first element of the vault to be constructed, work on the partition arch began on 24 October 1674; the keystone of this arch is located at the same level as the top of the large vault. The arch was already built, with a rise whose length is one canne and one and a half pan $(243 \mathrm{~cm})$ when the model was received at the beginning of November from Paris. Mansart wanted the height of the rise to be one and half pan less $(204.6 \mathrm{~cm})$. After a quick discussion, it was decided to leave the arch as it was and to carry on with the work.

The construction of the arch of the main entrance and of its penetration in the small oval vault, which had been drawn with straightedge and compass, followed the same procedure described above. It is important to note that the joint lines do not turn back on the penetration edge.

This fact shows that respect for the module on the lunette, as well as the aesthetic concern about the penetration curve, outweighed the definition of the volume, which his was therefore not defined. The concurrence of this drawing with the survey also provides proof of this hypothesis. 


\section{The stereotomy and its methods}

A number of different cutting techniques were used for the construction of this vault.

The first two rows, which are part of the outside wall (and which therefore would have been constructed first) are corbelled and therefore have been square cut. The two semidomes of the large vault, which follow surfaces of revolution, were probably cut by panel according to the method of truncated cones, which was quite traditional at the time. However, on the small vault, the semidomes are not regular, as mentioned earlier.

It is likely that the stones of the six rows of evolution were square cut.

It is also probable that, in view of the good implementation of the joint curves, the vault was constructed on a veau, the curve of an arch with a plastered surface where the joint curves were traced.

However, as far as the stones of the lunettes are concerned, a square cut seems impossible for the following reasons:

- the archives mention the fact that Mansart "baillera le trait à celui qui le conduira" (will teach those who carry out the work what to do) and Peytret spent approximately one month receiving "les instructions modèles et panneaux pour lesdits bâtiment et voûtes" (the instructions for the model and panels for the building and vaults). To be sure, Peytret did not need a month of apprenticeship with the master in order to use the square cut technique;

- A model was made out of wood for the large lunette, which also suggests the use of a more complex method than the square cut;

- We know that the square cut was not a method advocated by the Académie and Mansart himself would have been the last to have campaigned for its use;

- Last but not least, the square cut uses a huge quantity of stone at the level of the haunch of the vault, especially with the curved penetrations and for a vault of at least $50 \mathrm{~cm}$ thick.

The square cut is therefore excluded for the lunettes. But a traditional cutting by panel does not seem appropriate either. Indeed, all the intrados are warped, which eliminates the (numerous) drawings out of a flat intrados panel.

Moreover, the panel method requires different panels for each stone, given the irregularity of the stones on a same row and in between rows. This time consuming drawing does not seem to be compatible with either the rapidity with which the work progressed of the work or with the archives, which mention a limited number of patterns for the panels.

Given the complexity of this kind of vault, the traditional stereotomic methods are inadequate. We therefore maintain that the stonecutting method used was that called a la sauterelle (the name sauterelle comes from the name given by the workers to the 'false square'). Used in carpentry, this was a quick method for cutting arch stones, using simple angle transfers and without the need for drawing all the panels. The principle is as follows: to determine a polyhedron with six sides, it is necessary, for each corner, to know the angles of the edges which converge to it. Here one of the sides is warped but the knowledge of those angles is sufficient for the cutting. Starting from one of the joint plans, two segments of straight lines of the intrados - non coplanar segments - will make it possible to adjust the intrados during the cutting process. Figs. 30, 31 and 32 show respectively the drawing of the angles needed for the construction. 


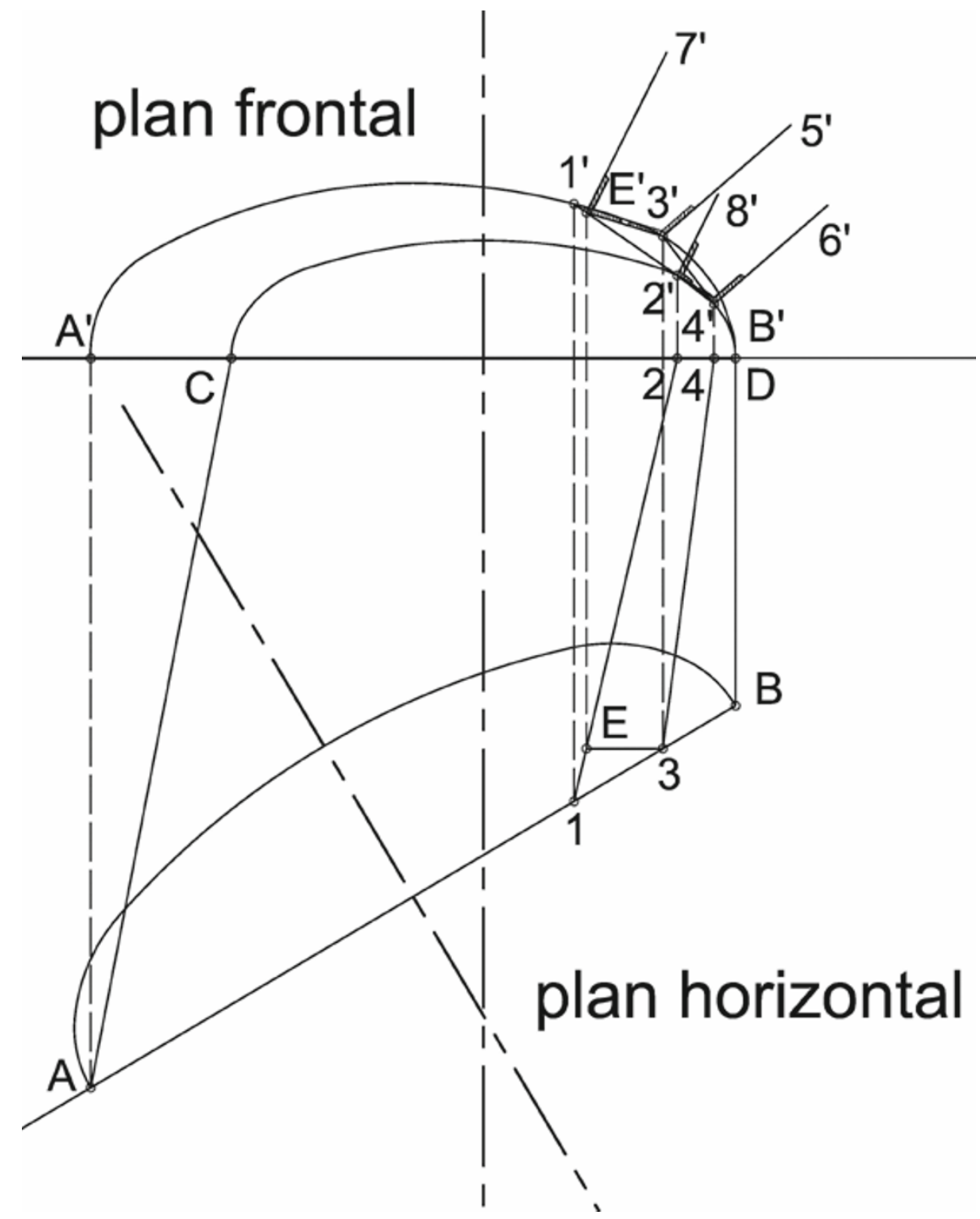

Fig. 30. Head angles. The lunette is defined by the arches $A B$ and $C D$, whose elevations are projected down to the plan. The arch $A B$ projects itself into frontal $A^{\prime} B^{\prime}$. Any given soffit is defined by its plan 1-2-3-4. In the terminology used in French carpentry, the frontal plan is "la herse" and the horizontal plan is "le plan". Segment $3 \mathrm{E}$ is a "chevron d'emprunt", that is, a construction line which is not the outline of the piece but a marker for its execution, and is parallel to the frontal plan. The straight line $6^{\prime}-4^{\prime}$ goes through one of the centers of arch CD. It makes it possible to define the joints of the voussoir: it is sufficient to consider a parallel line $3^{\prime}-5^{\prime}$ through the frontal plan $3 \mathrm{E}$. In the same way, we can define the other side of the joint $8^{\prime}-2^{\prime}-1^{\prime}-7^{\prime}$. The angles needed for cutting the stones appear on the frontal projection and will be measured using a sauterelle, an two-side adjustable template 


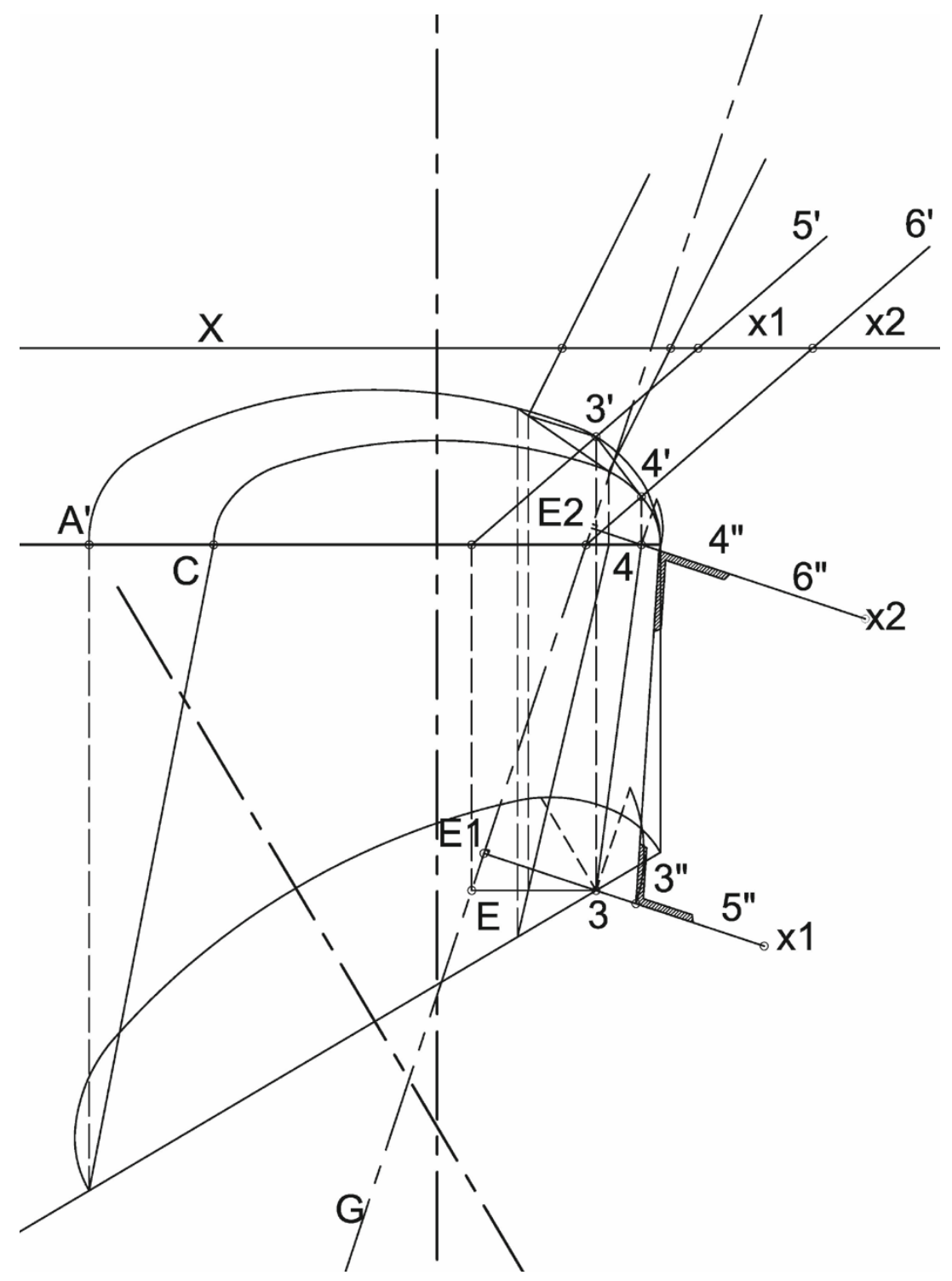

Fig. 31. Joint angles. The plan of the joints $\left(6^{\prime}-4^{\prime}-3^{\prime}-5^{\prime}\right)$ is projected down to the horizontal plan, and the angles of the bed is deduced from that. Also indicated in the figure is the horizontal plane $\mathrm{X}$. Taking the distances $3^{\prime}-\mathrm{x} 1$ and $4^{\prime}-\mathrm{x} 2$ allows you to locate $\mathrm{X}$ on the stone, and to square cut the penetration 


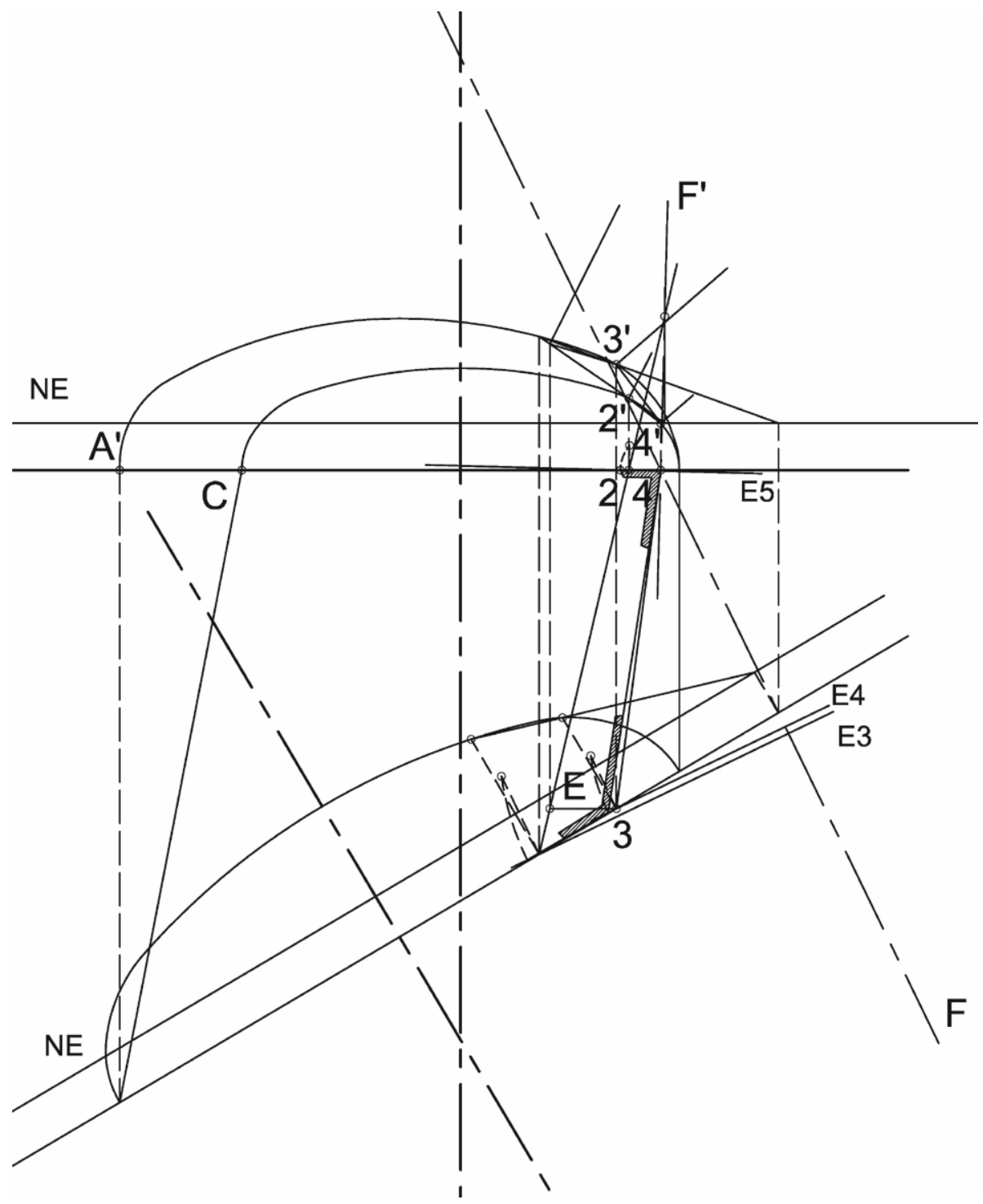

Fig. 32. Soffit angles. To obtain the real size of the angle, the plane defined by two straight lines 34 and $3-\mathrm{E}$ is rotated down around a horizontal hinge (for instance, the one which goes through point 3). In the same way, we can determine the angle for the two straight lines 3-4 and 2-4 thanks to a hinge going through 4 . A length transferred onto segments $3-\mathrm{E}$ and $2-4$ determine the second edge of the soffit 
The first French publication that dealt with sauterelle dates to the eighteenth century, but the method itself dates to before that, because it is described in the 1619 manuscript by Diego Lopez de Arenas. This Spanish manuscript provides us with information regarding the origin of the sauterelle, a method that appears to have been developed to deal with the complexity of geometric ornamentation inspired by Islamic art and architecture.

Another hypothesis regarding knowledge of this method derives from the fact that Girard Desargues used a method of double projection in order to take from the drawing the true dimension of the angles that the planes make with one another. Even though the arrangement and angles used by Desargues in his demonstrations are not anything like those of the sauterelle, the tools of projection are the same.

It is possible that Mansart came to learn about this method through studies of the works of Desargues during the three years he spent in the seminaries in Versailles, until 1673 , before his journey to the south.

For the penetration arch stones, the X plan is used (see fig. 31) on which the panel of the horizontal projection is applied. The penetration can be square cut since the radial joints of the small vault are vertical.

\section{Mansart's spatial vision}

Thoroughly knowledgeable in geometry and optics, Mansart knew that the human eye was not capable of perceiving whether the geometry of a surface was exact or not. Because he would not have been able to control the intersections of the portions of the vault, and thus the joints of the courses in space, he devised a solution: tracing the lines of the courses in plan and projecting them on the surfaces of the space would have fooled the human eye. For example, the arches of intersection between the small vault and the side lunettes, and between the large vaults and the side lunettes are exactly plane arches (represented in plan by line segments). The intersections between the cylindrical surface of the large arch and the cylindrical surface that connects the two semidomes of the large vault are also represented in plan as line segments, even though the two cylinders do not have the same radius of curvature. Thus in all probability the drawing of the courses were laid out in plan, and successively the blocks themselves were studied in order to confer on the structure the vision of the whole that the architect wanted to achieve. Obviously, there were some points in which it was not possible to create this kind of block, and so it was decided to draw the lines of the courses.

\section{Conclusions}

The daring construction of the vaulted space of the Hotel de ville had no successive echoes. The spatial studies that linked progress in the discipline of stereotomy to the quality of architectural space had by that time come to an end.

Jules Hardouin-Mansart possessed the necessary knowledge of geometrical technique and structural mechanics to be able to create an aesthetically-pleasing architecture. His work represents the culmination of stereotomic construction. The studies presented here were aimed at filling in the gaps in our knowledge of the vault by, for example, carrying out an accurate survey; but they are also useful for advancing our knowledge of the discipline of stereotomy. 


\section{References}

Androuet Du Cerceau, Jacques. 1988. Le plus excellents bastiments de France (1576-1579), Paris: Editions Sand.

BARRIELLE, Jean-Francois. 1982. Le style Louis XIV. Paris: Editions Flammarion.

Beaupre, Charles Mauricheau. 1948. Versailles, Les Documents d'Art. Munich: Editions Imprimerie Nationale.

BENOIT, Francois. 1935. Histoire municipale d'Arles. In Encyclopédie départementale, Bouche du Rhône.

BoIDI, Giuseppe. 1914. I cinque ordini del Vignola, da Manuale di disegno architettonico. Turin: Editions Momo.

Bosse, Abraham. 1643. La pratique du trait a preuve de Mr. Desargues Lyonnois, pour la Coupe des Pierres en l'Architecture. Paris: Editions Imprimerie de P. Des-Hayes.

Bougard, Jean-Francois. 2007. Les Maîtres Bâtisseurs ou la Science des Nombres. Paris: Editions Mosaique.

Bourget, Paul. - Cattani, G. 1956. Jules Hardouin Mansart. Paris: Editions Vincent, Freal \& C.

BOYER, Jean. 1969. Jules Hardouin Mansart et l'hotel de ville d'Arles. Arles: Ville d'Arles.

CArdone, Vito. 1996. Gaspard Monge, Scienziato della rivoluzione. Naples: Editions Cuen.

CHARvet, Leon. 1898. L'hotel de ville d'Arles, Réunion des Sociétés des Beaux-arts. Paris.

CHARVET, Leon. 1870. Les Royers de La Valfenière. Lyon.

CHASTEL, Andrè . 2006. L'Art Français ancient régime 1620-1775. Paris: Editions Flammarion.

CHITHAM, Robert. 1987., Gli ordini classici in architettura. Milan: Editions Hoepli.

De La Hire, Philippe. 1687-1690. Traité de la coupe des pierres. Paris: Bibliotheque de l'Institut de France, Ms. 1596.

De LA Rue, Jean Baptiste. 1728. Traité de la coupe des pierres. Paris: Imprimerie Royale.

Delorme, Philibert. 1567. Le premier tome de l'architecture. Paris: Editions Morel.

FALlaCARA, Giuseppe. 2007. Verso una progettazione stereotomia. Bari: Editions Aracne.

FrEZIER, Amédée-François. 1737-1739. La théorie et la pratique de la coupe des pierres et des bois ... ou traité de stéréotomie a l'usage de l'architecture. Strasbourg-Paris: Jean Daniel Doulsseker-L. H. Guerin.

GIORDANO, Andrea. 1999. Cupole, volte e altre superfici. La genesi e la forma. Turin: Utet.

GUARINI, Guarino. 1968. Architettura civile (1737). Milan: Il Polifilo.

Heijmans, Marc, J. M. RouQUeTtE and C. SinTES. 2006. Arles antique, guide archéologiques de la France. Paris: Editions du patrimoine.

KoENIG, Giovanni Klaus, et al. 1993. Tecnologia delle costruzioni. Florence: Editions Le Monnier.

MAsSot, Jean Luc. 1992. Architecture e Décoration du XVI au XIX siècle. Vol. 2 of L'art de Restaurer en provence. Salerno: Editions Edisud.

Michel, Alain. 1980. Au Pays d'Arles. Planches hors texte. Arles: Editions Arthaud.

Migliari, Riccardo. 2000. Il disegno e la pietra. Rilievo e Stereotipia. Rome: Editions Cangemi.

Monge, Gaspard. 1900. Géométrie Descriptive (1798-1799). Paris: Editions Baudouin Imprimeur du Corps Legislatifs et de l'Institut National.

Mottana, Annibale, Rodolfo Crespi and Giuseppe Liborio. 1985. Minerali e rocce. Milan: Editions Arnoldo Mondadori.

Perouse De Montclos, Jean Marie. 1982. L'architecture à la française. Paris: Editions Picard.

- 1983. La voûte de l'Hôtel de ville d'Arles est-elle le produit de la tradition locale ou une importation parisienne? Travaux et colloques de l'Institut d'art. Publications de l'Université de Provence.

PEZET, Maurice. 1982. Les belles heures du pays d'Arles. Marseille: Editions Jeanne Laffitte.

Rondelet, Jean. 2005. Trattato teorico e pratico dell'arte di edificare (1802-1817). Rome: Editions Librerie Dedalo.

Saule, Beatrix. - MeYer, D. 2007. Versailles. Guida per la visita. Versailles: Editions Art Lys.

TAMBORÉRO, Luc and Joël SAKAROVITCH. 2003. The vault of Arles City Hall: a carpentry outline for a stone vault? Pp. 1899-1907 in vol. III of Proceedings of the First International Congress on Construction History, Madrid, 20-24 January 2003, Santiago Huerta, ed. Madrid: Instituto Juan de Herrera, Escuela Técnica Superior de Arquitectura. 
Toman, Rolf. 1998. L'art du Baroque Architecture. Sculpture. Peinture. Paris: Editions Konemann.

\section{About the authors}

Giuseppe Fallacara is an architect and researcher at the Faculty of Architecture at the Polytechnic of Bari. Since 2005 he has conducted experiments in stereotomy with the creation of construction elements in stone. Examples are: Escalier Ridolfi, an entry portal for the Venice Biennale (a variation of the Abeille vault), Alexandros obelisk, pre-stressed stone arch built in Brignoles, Toulon (France), arch leaf in Parabita, Lecce (Italy), free-standing stereotomic wall hangings, etc. His publications include: Verso una progettazione stereotomica (Rome: Aracne, 2007), Plaited Stereotomy. Stone Vaults for the Modern World (with R. Etlin and L. Tamboréro; Rome: Aracne, 2008) and Domus Benedictae: villa unifamiliare a Corato (Collana Archinauti, 27; Bari: PoliBa Press, 2010).

Fiore Resta is an architect. He holds a Ph.D. from the Faculty of Architecture of the Politecnico di Bari, in Architectural Design for the countries of the Mediterranean. His thesis is entitled "Spaces of vaults and domes in the architecture of Jules Hardouin-Mansart."

Nicoletta Spallucci is an architect. She holds a Ph.D. from the Faculty of Architecture of the Politecnico di Bari, in Architectural Design for the countries of the Mediterranean. Her thesis is entitled "Vaulted roofs and domes of the Cistercian abbeys restored by Viollet-Le-Duc."

Luc Tamboréro has been a master stonemason since 1995 . He is currently a Ph.D. candidate in Architecture at the laboratory Geometry, Structure, Architecture of the Ecole d'Architecture ParisMalaquais under the advisement of Joël Sakarovitch. He studied materials and techniques in France under the terms of Compagnon du Devoir. For several years he and his company, Mecastone, have worked on construction sites of both new buildings and restoration projects in different countries. He has produced prototypes for a new building in solid stone. 